\title{
Kinetic and Equilibrium Studies on the Zinc Adsorption-desorption Characteristics of Some Promising Biochars in Aqueous Solutions
}

Masoumeh Faryadi Shahgoli

University of Tabriz

Adel Reyhanitabar ( $\nabla$ areyhani@tabrizu.ac.ir)

University of Tabriz https://orcid.org/0000-0003-1066-9130

Nosratollah Najafi

University of Tabriz

Shahin Oustan

University of Tabriz

Research Article

Keywords: Adsorption, Biochar, Desorption, lonic strength, $\mathrm{pH}$, Zinc

Posted Date: March 16th, 2021

DOI: https://doi.org/10.21203/rs.3.rs-252281/v1

License: (9) This work is licensed under a Creative Commons Attribution 4.0 International License.

Read Full License 


\section{Title Page}

2

Kinetic and equilibrium studies on the zinc adsorption-desorption characteristics of some promising biochars in aqueous solutions Masoumeh Faryadi Shahgoli ${ }^{1}$, Adel Reyhanitabar ${ }^{2}$, Nosratollah Najafi $^{3}$ and Shahin Oustan ${ }^{4}$

1. Ph.D. student, Department of Soil Science, Faculty of Agriculture, University of Tabriz, Tabriz, Iran. E-mail: masoomeh.faryadi@yahoo.com

2. Associate Professor, Department of Soil Science, Faculty of Agriculture, University of Tabriz, Tabriz, Iran.

3. Professor, Department of Soil Science, Faculty of Agriculture, University of Tabriz, Tabriz, Iran. Email: nanajafi@yahoo.com

4. Professor, Department of Soil Science, Faculty of Agriculture, University of Tabriz, Tabriz, Iran. Email: oustan@hotmail.com

*Corresponding Author e-mail: areyhani@tabrizu.ac.ir, Alternative email: areyhanitabar@ yahoo.com Tel: +98-9141181401 and Fax: +98-41-33345332

\section{A concise and informative title:}

Biochar effects on the zinc adsorption-desorption in aqueous solutions 

aqueous solutions

\begin{abstract}
The present research aimed at investigating zinc (Zn) sorption capacity of the biochars derived from apple wood (WB) and rice straw (RB) feedstocks at two 300 and $600{ }^{\circ} \mathrm{C}$ pyrolysis temperatures (WB300, WB600, RB300 and RB600, respectively) in aqueous solutions. Kinetic and equilibrium sorption experiments were conducted via batch technique. In equilibrium adsorption experiments, the study used the concentration range of 5-200 $\mathrm{mg} \mathrm{Zn} \mathrm{L}^{-1}$ and focused on the solution $\mathrm{pH}$ effect on $\mathrm{Zn}$ adsorption in biochars under the following conditions: unadjusted and adjusted $\mathrm{pH}(4$ and 6$)$ and three ionic strength levels $\left(0.01,0.03,0.1 \mathrm{M} \mathrm{KNO}_{3}\right)$. Zinc desorption experiments were conducted under all above mentioned conditions but without $\mathrm{pH}$ adjustment at five separate stages. Kinetic data analysis indicated that $\mathrm{Zn}$ adsorption in biochars reached the near steady state within 24 hours with the sorption rate order of WB300 < WB600 < RB300 < RB600. The best fitness was superior to both Elovich and exponential rate models. Also, $\mathrm{Zn}$ adsorption isotherms in the studied biochars were shown to fit quite well to Langmuir, Freundlich and Dubinin-Radushkevich models. Zn sorption maxima were found to be $4.3,16.4,17.9$ and $33.3 \mathrm{mg} \mathrm{g}^{-1}$, on average, for WB300, WB600, RB300, and RB600, respectively. The initial increased pH solution from 4 to 6 caused an increase in $\mathrm{Zn}$ adsorption in RB600, RB300 and WB600, however the sorption maxima in WB300 was detected at $\mathrm{pH} 4$. The rise in solution ionic strength from $0.01 \mathrm{M}$ to $0.1 \mathrm{M}$ dropped the $\mathrm{Zn}$ adsorption capacity in all the studied biochars. Findings suggested that rice straw derived biochars showed a better performance than woody biochars in $\mathrm{Zn}$ sorption and retention from aqueous solutions. In addition, this ability increased with increasing pyrolysis temperature in both types of biochars. Finally, the study revealed that rice straw biochars, produced at high pyrolysis temperatures, can serve as economical and efficient absorbents for $\mathrm{Zn}$ removal from aqueous solutions.
\end{abstract}

Keywords: Adsorption, Biochar, Desorption, Ionic strength, $\mathrm{pH}$, Zinc

\title{
1. Introduction
}

Biochars are porous, fine-grained, pyrolyzed biosorbents derived from plant and animal residues in oxygen-limited conditions (Shackley et al., 2012). Characteristics and applications of these environment-friendly materials are dictated mainly by variations in feedstock type and pyrolysis conditions. As the pyrolysis temperature rises, the organic substances evaporate or decompose which leads to a higher ash content. This is closely associated with $\mathrm{pH}$ rise in response to increased content of alkali and alkali earth carbonates and oxides. This may be the result of the decreased functional groups such as $-\mathrm{COOH}$ (Jin et al., 2016).

The decision to apply the effective sorbent for heavy metals depends on adsorption rate and capacity, mechanical strength, and economical efficiency. Though activated carbon meets all the requirements, it is hardly a favorable choice due to high production costs. Here, biochar can be a good alternative because of low-cost and simple production technology. Biochar surfaces are less carbonized and contain more oxygen-containing groups compared to activated carbon. However, its adsorption capacity for heavy metals varies depending on biomass type and pyrolysis conditions as well as the heavy metal type (Ni et al., 2019). Many studies indicate that biochars derived from agricultural wastes can be used as an appropriate sorbent for heavy metals in soil and water systems because of high specific surface area and abundant oxygencontaining functional groups as well as high precipitating anions (Park et al., 2016; O'Connor et al., 2018). It should be noted that metal adsorption on biochar surfaces is determined by $\mathrm{pH}$ level. In $\mathrm{pH}<\mathrm{pH}$ PZC, most functional groups with positive charge can adsorb anions, while in $\mathrm{pH}_{\mathrm{PZC}}<\mathrm{pH}$, their negative charge can easily adsorb cations (Abdel-Fattah et al., 2015). Biochar-based sorption mechanisms of metals from solutions include electrostatic interaction between the heavy metals and biochar surface, cation exchange between metals and protons or between alkaline cations on biochar surface, complexations between metals and functional groups and $\pi$ electrons on the aromatic structure of biochar, and metal precipitation (Cui et al., 2016). Studies confirm that metal sorption mechanisms may be attributed to biochar characteristics such as ash concentration, specific surface area and zeta potential value, all of which are appropriate in the case of heavy metals (Ding et al., 2016).

Zinc $(\mathrm{Zn})$ is a heavy metal with toxic properties in high concentrations, but it is essential nutrient to plant growth in low concentrations. There is not a wealth of literature on $\mathrm{Zn}$ sorption mechanisms by biochar; however, it would be possible to focus on precipitation with oxyanions such as $\mathrm{PO}_{4}^{-3}$ and $\mathrm{CO}_{3}^{-2}$, ion exchange with metals like $\mathrm{K}^{+}, \mathrm{Na}^{+}, \mathrm{Ca}^{+2}$ and $\mathrm{Mg}^{+2}$, surface complexation with oxygen-containing functional groups such as $-\mathrm{COOH}$ and $-\mathrm{OH}$, and dative bond with $\pi$ electrons of $\mathrm{C}=\mathrm{C}$ and $\mathrm{C} \equiv \mathrm{C}$ in aromatic complexes as possible mechanisms ( $\mathrm{Li}$ et al., 2017). Heavy metal adsorption capacities may vary depending on biochar type. For instance, $\mathrm{Zn}$ sorption capacity in biochars derived from pig and cow manures is reported to be 50-81 $\mathrm{mg} \mathrm{g}^{-1}$; however, the respective value for $\mathrm{Cu}, \mathrm{Cd}$ and $\mathrm{Pb}$ are 75-95, 80-122 and 154-230 $\mathrm{mg} \mathrm{g}^{-1}$ (Kolodyńska et al., 2012). Chen et al. (2011) quantified the Zn sorption capacity of wood derived biochar at 6.8 $\mathrm{mg} \mathrm{g}^{-1}$ in aqueous solutions, but this rose to $12.5 \mathrm{mg} \mathrm{g}^{-1}$ when corn straw derived biochar was used. In another study, Frišták et al. (2015) reported the sorption capacity of $0.9-2.2 \mathrm{mg} \mathrm{g}^{-1}$ for biochars derived from beech wood chips and garden green wastes. Those derived from sesame straw and pyrolyzed at $700{ }^{\circ} \mathrm{C}$ biochar indicated a $\mathrm{Zn}$ sorption maxima 
of $34 \mathrm{mg} \mathrm{g}^{-1}$ (Park et al., 2016). According to Abdelhadi et al. (2017), the biochar derived from olive solid waste at 350 ${ }^{\circ} \mathrm{C}$ pyrolysis temperature exhibited an 80 percent cumulative removal capacity for $\mathrm{Cu}, \mathrm{Pb}, \mathrm{Cd}, \mathrm{Ni}$ and $\mathrm{Zn}$ in solution systems. Van Hien et al. (2020) reported that the Zn sorption rate followed the order of rice husk < wood <bamboo as biochar sources, where the bamboo with the sorption capacity of $12.5 \mathrm{~g} \mathrm{~L}^{-1}$, accounted for $96 \% \mathrm{Zn}$ removal in the solution with the initial concentration of $80 \mathrm{mg} \mathrm{L}^{-1}$. Zhao et al. (2020) found that the sorption capacity of biochars from rice husk, chicken manure, and sewage sludge for $\mathrm{Pb}$ was higher than that for $\mathrm{Zn}$. The study suggested that $\mathrm{Zn}$ sorption in biochars can greatly depend on the nature of feedstock biomass.

With this background in the literature, the present study aimed at deriving biochars from rice straw in Northern Iranian Province, and wood chips from apple tree pruning as part of agricultural and garden waste in Northwest of Iran. Heavy metal sorption-desorption reactions in the environment are crucial processes upon which $\mathrm{Zn}$ retention depends. The main objectives of this study are as follows:

1) Assessing the impact of biomass type and pyrolysis temperature on physical and chemical properties of the derived biochars;

2) Assessing the derived biochars in $\mathrm{Zn}$ sorption-desorption and determining $\mathrm{pH}$ and solution ionic strength effects on the biochar's sorption capacity; and

3) Obtaining kinetic and isotherm parameters from $\mathrm{Zn}$ sorption-desorption experiments.

\section{Materials and methods}

\subsection{Preparation of biochars}

Biochars used in this study were derived from apple wood and rice straw feedstocks. The former was gathered from the apple orchards around Urumia and the latter from paddies around Rasht, respectively in Northwest and North of Iran. After collection, the biomass samples were washed with water and air-dried, then crushed and sieved to $<1 \mathrm{~mm}$ particles. Slow pyrolysis technique was employed inside an oxygen-limited electrical furnace with argon flow rate of $2.5 \mathrm{~L} \mathrm{~min}{ }^{-1}$. The furnace was programmed to provide the pyrolysis temperatures to 300 and $600{ }^{\circ} \mathrm{C}$ at a rise rate of $10{ }^{\circ} \mathrm{C} \mathrm{min}^{-1}$. The maximum temperatures was held for one-hour (Cui et al., 2016). Then, the furnace was turned off and the produced biochars were cooled down to reach ambient temperature. The biochars derived from apple wood and rice straw at 300 and $600{ }^{\circ} \mathrm{C}$ pyrolysis temperatures were labeled WB300, and WB600, RB300 and RB600, respectively.

\subsection{Characteristics of biochars}

First, the biochar samples were dried in the oven at $105^{\circ} \mathrm{C}$ for 2 hours. Then, they were subjected to combustion in the furnace at $750^{\circ} \mathrm{C}$ for 6 hours and the ash content was calculated by measuring the ratio of ash weight to the total biochar weight (Al-Wabel et al., 2013). The $\mathrm{pH}$ and EC values of the biochars were measured at a 1:10 ratio (biochar to distilled water) after shaking for 30 minutes (Lee et al., 2013). Carbon (C), hydrogen $(\mathrm{H})$, and nitrogen $(\mathrm{N})$ concentration of the biochars were determined using CHNS Analyzer (Elementer, Vario EL III), and the oxygen content was calculated in terms of weight difference $(100-\Sigma(C+H+N+S+$ ash $)$ percents $)$. In order to obtain the total concentration of other elements in the biochar, dry ashing method was used (Westerman, 1990). P and K concentrations were measured by spectrophotometer (Philler Scientific, SU6100) and flame photometer (Model Corning, 410), respectively. The concentrations of $\mathrm{Ca}, \mathrm{Mg}, \mathrm{Fe}, \mathrm{Zn}, \mathrm{Cu}$ and $\mathrm{Mn}$ were analyzed using atomic absorption spectrometer (Shimadzu, AA-6300). Functional groups were assessed using Fourier-transform infrared spectroscopy (FTIR) (Bruker, Tensor 27), and the morphology and microstructure of the produced biochars were investigated using scanning electron microscope (TESCAN, MIRA3FEGSEM). Specific surface area of the biochars was measured based on standard BET method using $\mathrm{N}_{2}$ gas sorption-desorption isotherms. To determine point of zero charge ( $\mathrm{pH}_{\mathrm{PZC}}$ ), the authors employed mass titration method as described by Noh and Schwarz (1990). Acidic functional groups on biochar surfaces were also identified through Bohem titration (Tsechansky and Graber, 2014). Also, biochar cation exchange capacities (CECs) were evaluated by extracting the biochars with $1 \mathrm{M}$ sodium acetate solution at $\mathrm{pH} 7$.

\subsection{Adsorption and desorption isotherms}

$\mathrm{Zn}$ adsorption-desorption experiments were conducted using the batch technique. For this, $\mathrm{Zn}$ solutions were prepared by dissolving zinc nitrate $\left(\mathrm{Zn}\left(\mathrm{NO}_{3}\right)_{2} .6 \mathrm{H}_{2} \mathrm{O}\right)$ and potassium nitrate $\left(\mathrm{KNO}_{3}\right)$ in distilled water. Kinetic adsorption experiments were conducted in $50 \mathrm{~mL}$ centrifuge tubes using $0.1 \mathrm{~g}$ duplicate subsamples of each biochar in $20 \mathrm{~mL}$ background electrolyte solution $\left(0.03 \mathrm{M} \mathrm{KNO}_{3}\right)$ containing $200 \mathrm{mg} \mathrm{Zn} \mathrm{L}^{-1}$, without $\mathrm{pH}$ adjustment. The tubes were agitated on a shaker at $120 \pm 5 \mathrm{rpm}$ and $25 \pm 1{ }^{\circ} \mathrm{C}$ for contact times of $0.5,1,2,4,8,12,16,24,32,48$ and 64 hours. Then, the tubes were centrifuged at $6000 \mathrm{rpm}$ for 10 minutes and the supernatant was filtered through a Whatman filter. The concentration of $\mathrm{Zn}$ in solution was measured by Atomic absorption spectrophotometer (Shimadzo AA-6400). in $20 \mathrm{~mL}$ background electrolyte solution (at three levels of ionic strength $0.01,0.03$, and $0.1 \mathrm{M}^{\circ} \mathrm{KNO}_{3}$ ) containing 
different initial $\mathrm{Zn}$ concentrations $\left(5,10,20,40,60,80,100,150,200 \mathrm{mg} \mathrm{L}^{-1}\right)$ with three initial $\mathrm{pH}$ values (unadjusted $\mathrm{pH}$, adjusted $\mathrm{pH}$ at 4 and 6) adjusted by $0.1 \mathrm{~mol} \mathrm{~L}^{-1} \mathrm{HNO}_{3}$ and $0.1 \mathrm{~mol} \mathrm{~L}^{-1} \mathrm{NaOH}$ solutions. The reaction mixture was shaken at $25 \pm 1{ }^{\circ} \mathrm{C}$ for 24 hours. After reaching equilibrium, the tubes were centrifuged at $6000 \mathrm{rpm}$ for 10 minutes and the supernatant was were filtered and analyzed for $\mathrm{Zn}$ concentration. The adsorption amount $\left(\mathrm{q}_{\mathrm{e}}, \mathrm{mg} \mathrm{g}^{-1}\right)$ and removal efficiency were calculated according to Equation 1 and Eq. 2: (Wang et al., 2015).

$q_{e}=\frac{\left(C_{i}-C_{e}\right) V}{m}$

Removal efficiency $(\%)=\frac{C_{i}-C_{e}}{C_{i}} \times 100$

where, $\mathrm{C}_{\mathrm{i}}$ and $\mathrm{C}_{\mathrm{e}}$ are initial and equilibrium concentrations $\left(\mathrm{mg} \mathrm{L}^{-1}\right)$, respectively; $\mathrm{m}$ stands for biochar weight in terms of $\mathrm{g}$, and $\mathrm{V}$ is the volume of solution (L).

Desorption experiments were conducted at the end of adsorption experiments. For this, the initial $\mathrm{Zn}$ concentration of $200 \mathrm{mg} \mathrm{L}^{-1}$ at all levels of ionic strength under unadjusted $\mathrm{pH}$ condition was employed. At the end of adsorption experiment, $15 \mathrm{~mL}$ of supernatant was removed and $15 \mathrm{~mL}$ of background solution $\left(0.03,0.01\right.$, and $0.1 \mathrm{M} \mathrm{KNO}_{3}$ ) was added to the tubes. The tubes were shaken for the equilibrium time and then centrifuged. A total of five desorption stages were accomplished. Finally, the amount of desorbed $\mathrm{Zn}$ at each stage was calculated by applying equation (1), in which $\mathrm{C}_{\mathrm{i}}$ is the initial concentration in each desorption stage that is obtained through dividing the final concentration $\left(\mathrm{C}_{\mathrm{e}}\right)$ of the preceding stage, by the degree of dilution resulting from adding the background solution (Yang et al., 2018). Total desorption efficiency was derived from the following equation:

Desorption efficiency $=\frac{\mathrm{q}_{\text {des }}}{\mathrm{q}_{\mathrm{ads}}} \times 100$

Where $\mathrm{q}_{\text {ads }}$ is the amount of adsorbed $\mathrm{Zn}$ and $\mathrm{q}_{\mathrm{des}}$ stands for $\mathrm{Zn}$ desorbed.

\subsection{Models of adsorption kinetic and isotherm}

Pseudo first-order, pseudo second-order, parabolic diffusion, exponential and Elovich models were tested for their suitability to describe the kinetics of Zn sorption by studied biochars (Table 1). Additionally, the Freundlich, Langmuir and Dubinin-Radushkevich models were employed to fit the adsorption results,.

Polanyi potential $(\varepsilon)$ in Dubinin-Radushkevich equation can be obtained from Eq. (4) :

$\varepsilon=\operatorname{RT} \operatorname{Ln}\left[1+\frac{1}{\mathrm{C}_{\mathrm{e}}}\right]$

where, $\mathrm{R}$ is universal gas constant $\left(0.008314 \mathrm{~kJ} \mathrm{~mol}^{-1}{ }^{\circ} \mathrm{K}^{-1}\right), \mathrm{T}$ is temperature $\left({ }^{\circ} \mathrm{K}\right)$ and $\mathrm{C}_{\mathrm{e}}$ is equilibrium concentration in the solution $\left(\mathrm{mg} \mathrm{L}^{-1}\right)$.

In the Dubinin-Radushkevich model, $K_{D}$ is used for calculating mean free energy $\left(E=1 / \sqrt{ } 2 K_{D}\right)$. If $E$ is less than $8 \mathrm{~kJ}$ $\mathrm{mol}^{-1}$, physical adsorption is assumed, but if its value occurs in the range of 8 to $16 \mathrm{~kJ} \mathrm{~mol}^{-1}$, then the assumed adsorption type will be chemical (Chabani et al., 2006).

Table 1. Kinetic and isotherm models used in this study.

\begin{tabular}{|c|c|c|}
\hline Model & Equation & Parameters \\
\hline Pseudo-first order & $q_{t}=q_{e}\left(1-\exp \left(-k_{1} t\right)\right)$ & $\mathrm{k}_{1}$ : adsorption rate constant $\left(\right.$ hour $\left.^{-1}\right)$ \\
\hline $\begin{array}{l}\text { Pseudo-second } \\
\text { order }\end{array}$ & $q_{t}=\frac{k_{2} q_{e}^{2} t}{1+k_{2} q_{e} t}$ & $\mathrm{k}_{2}$ :adsorption rate constant $\left(\mathrm{mg}^{-1} \mathrm{~g}\right.$ hour $\left.{ }^{-1}\right)$ \\
\hline Parabolic diffusion & $q_{t}=q_{0}-k_{p} t^{\frac{1}{2}}$ & $\mathrm{k}_{\mathrm{p}}$ : diffusion rate constant $\left(\mathrm{mg}^{-0.5} \mathrm{~g}^{0.5}\right)$ \\
\hline Exponential & $q_{t}=a t^{b}$ & $\begin{array}{l}\text { a: initial adsorption rate constant }\left(\mathrm{mg} \mathrm{g}^{-1} \text { hour }{ }^{-1}\right) \\
\text { b: adsorbtion rate coefficient }\left(\left(\mathrm{mg} \mathrm{g}^{-1}\right)^{-1}\right)\end{array}$ \\
\hline Elovich & $\mathrm{q}_{\mathrm{t}}=\frac{1}{B} \operatorname{Ln}(a B \mathrm{t}+1)$ & $\begin{array}{l}a \text { : initial adsorption rate constant }\left(\mathrm{mg} \mathrm{g}^{-1} \text { hour }{ }^{-1}\right) \\
B \text { : adsorption constant }\left(\mathrm{mg}^{-1} \mathrm{~g}\right)\end{array}$ \\
\hline Freundlich & $q_{e}=K_{F} C_{e}^{\frac{1}{n}}$ & $\begin{array}{l}\mathrm{K}_{\mathrm{F}} \text { : relative adsorption capacity }\left(\mathrm{mg} \mathrm{g}^{-1}\right) \\
\mathrm{n} \text { : intensity of adsorption }\end{array}$ \\
\hline Langmuir & $q_{e}=\frac{q_{m} K_{L} C_{e}}{1+K_{L} C_{e}}$ & $\begin{array}{l}\mathrm{q}_{\mathrm{m}}: \text { maximum adsorption capacity }\left(\mathrm{mg} \mathrm{g}^{-1}\right) \\
\mathrm{K}_{\mathrm{L}}: \text { Langmuir constant }\left(\mathrm{L} \mathrm{mg}^{-1}\right)\end{array}$ \\
\hline $\begin{array}{l}\text { Dubinin- } \\
\text { Radushkevich }\end{array}$ & $q_{e}=\left(q_{m}^{\prime}\right) \exp \left(-\mathrm{K}_{D} \varepsilon^{2}\right)$ & $\begin{array}{l}\mathrm{q}_{\mathrm{m}}{ }^{\prime}: \text { maximum adsorption capacity }\left(\mathrm{mg} \mathrm{g}^{-1}\right) \\
\mathrm{K}_{\mathrm{D}}: \text { constant related to the adsorption energy }\left(\mathrm{mol}^{2}\right. \\
\left.\mathrm{Kj}^{-2}\right) \\
\varepsilon: \text { adsorption potential }\left(\mathrm{kJ} \mathrm{mol}^{-1}\right)\end{array}$ \\
\hline
\end{tabular}


A relatively high value of the coefficient of determination $\left(\mathrm{r}^{2}\right)$ and low value of the standard error of estimate (SEE) were used as the criterion for the best-fit equations for kinetic and isotherm data. The standard error of estimate was calculated using Excel software as follows:

$\mathrm{SEE}=\left[\frac{\sum\left(\mathrm{q}-\mathrm{q}^{\prime}\right)^{2}}{\mathrm{n}-2}\right]^{0.5}$

where $\mathrm{q}$ and $\mathrm{q}^{\prime}$ are the measured and calculated adsorption capacity, respectively, and $\mathrm{n}$ is the number of measurements. GraphPad Prism 8 software was used for calculating the kinetic and isotherm equation parameters as well as the values of determination coefficient $\left(\mathrm{r}^{2}\right)$ via non-linear regression method.

\section{Results and discussion}

\subsection{Physicochemical properties of biochars}

Properties of the biochars produced in this study are presented in Table 2. The ash concentration of RB300 and RB600 were higher than those of WB300 and WB600. The high ash content of rice straw biochars resulted from accumulation of various inorganic components during pyrolysis. Comparisons indicate that $\mathrm{pH}$ values of rice biochars were higher than those of woody biochars which in turn supports a close association between $\mathrm{pH}$ and elemental composition of biomass (Lie et al., 2017).

As expected, the higher the pyrolysis temperature, the higher the EC value, which can be attributed to high levels of soluble salts containing $\mathrm{K}^{+}$ions (Reyhanitabar et al., 2020).

Table 2. Physicochemical characteristics of the studied biochars.

\begin{tabular}{|c|c|c|c|c|}
\hline \multirow{2}{*}{ Property } & \multicolumn{4}{|c|}{ Biochar } \\
\hline & WB300 & WB600 & RB300 & RB600 \\
\hline $\operatorname{Ash}(\%)$ & 6.7 & 11 & 16 & 23 \\
\hline $\mathrm{pH}$ & 5.3 & 8 & 6.3 & 9.6 \\
\hline $\mathrm{EC}\left(\mathrm{dS} \mathrm{m^{-1 }}\right)$ & 0.331 & 1.2 & 2.8 & 5.6 \\
\hline $\mathrm{C}(\%)$ & 62.63 & 66.69 & 44.48 & 51.92 \\
\hline $\mathrm{N}(\%)$ & 0.68 & 0.52 & 1.56 & 1.33 \\
\hline $\mathrm{H}(\%)$ & 3.06 & 1.99 & 2.38 & 1.65 \\
\hline $\mathrm{O}(\%)$ & 26.93 & 19.80 & 35.58 & 22.1 \\
\hline $\mathrm{H} / \mathrm{C}^{*}$ & 0.58 & 0.36 & 0.64 & 0.38 \\
\hline $\mathrm{O} / \mathrm{C}^{*}$ & 0.32 & 0.22 & 0.60 & 0.32 \\
\hline $\operatorname{CEC}\left(\mathrm{cmol}_{\mathrm{c}} \mathrm{kg}^{-1}\right)$ & 88.17 & 59.65 & 106.85 & 82.95 \\
\hline $\mathrm{S}_{\mathrm{BET}}\left(\mathrm{m}^{2} \mathrm{~g}^{-1}\right)$ & 1.93 & 147.66 & 7.79 & 81.58 \\
\hline $\mathrm{pH}$ PZC & 4.10 & 6.75 & 6.20 & 9.35 \\
\hline Functional Carboxylic & 0.15 & 0.09 & 0.25 & 0.07 \\
\hline groups (mmol & 0.11 & - & 0.11 & 0.18 \\
\hline Phenolic & 0.08 & 0.20 & 0.30 & 0.12 \\
\hline $\mathrm{P}\left(\mathrm{g} \mathrm{kg}^{-1}\right) * *$ & 0.22 & 1.26 & 1.38 & 2.51 \\
\hline $\mathrm{K}\left(\mathrm{g} \mathrm{kg}^{-1}\right)$ & 2.85 & 11.09 & 36.54 & 68.41 \\
\hline $\mathrm{Ca}\left(\mathrm{g} \mathrm{kg}^{-1}\right)$ & 2.86 & 6.50 & 17.46 & 23.48 \\
\hline $\operatorname{Mg}\left(\mathrm{g} \mathrm{kg}^{-1}\right)$ & 0.74 & 1.04 & 4.03 & 7.41 \\
\hline $\mathrm{Fe}\left(\mathrm{mg} \mathrm{kg}^{-1}\right)$ & 88.4 & 495.43 & 489.17 & 912.65 \\
\hline $\mathrm{Zn}\left(\mathrm{mg} \mathrm{kg}^{-1}\right)$ & 13.0 & 32.89 & 22.14 & 58.91 \\
\hline $\mathrm{Cu}\left(\mathrm{mg} \mathrm{kg}^{-1}\right)$ & 22.98 & 71.50 & 37.77 & 87.78 \\
\hline $\operatorname{Mn}\left(\mathrm{mg} \mathrm{kg}^{-1}\right)$ & 36.54 & 97.2 & 43.50 & 91.08 \\
\hline
\end{tabular}

* Molar ratio ** $\mathrm{P}, \mathrm{K}, \mathrm{Ca}, \mathrm{Mg}, \mathrm{Fe}, \mathrm{Zn}, \mathrm{Cu}$ and $\mathrm{Mn}$ refer to total concentration of the respective elements.

As for CEC, at both pyrolysis temperatures, the CEC of wood based biochar was lower than that of rice based biochar and a rise in pyrolysis temperature caused a drop in CEC, which is supported in the literature (Cely et al., 2015). The rise in pyrolysis temperature led to a decrease in $\mathrm{O} / \mathrm{C}$ ratio, and an increase in aromatic compounds eventually causing $\mathrm{CEC}$ decline. CEC can be a criterion for assessing the contribution of ion exchange mechanism in $\mathrm{Zn}$ sorption. On the other hand, a decrease in CEC in the case of WB600, and RB600 probably indicates a lower importance of ionic exchange in Zn sorption by these biochars as compared to WB300 and RB300. Higher O/C molar ratio in RB300 and WB300 confirms that there are more polar functional groups and higher surface hydrophilicity in these biochars. Specific surface area in both type of grass- and wood-based biochars were linked with the rise in pyrolysis temperature, ultimately resulting in increasing channel structures. However, the rate of increase in specific surface area was higher in woody biochars. This, 
too, is in line with the earlier studies (Reyhanitabar et al., 2020). Concentration of all the assessed elements increased with pyrolysis temperature in both feedstock types. Also, for rice derived biochars the corresponding amounts exceeded those of woody biochars.

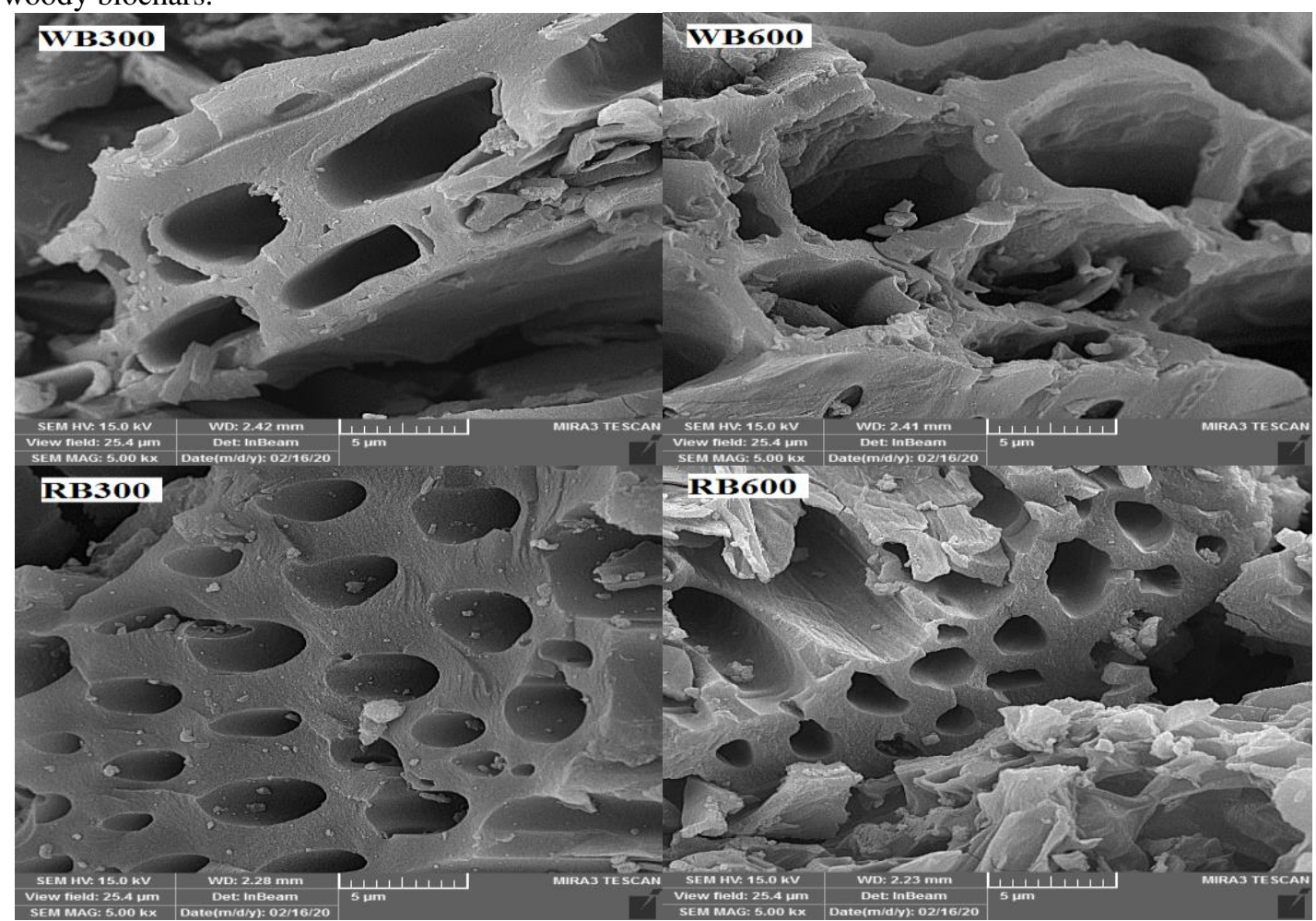

Figure 1. Scanning electron micrographs of WB300, WB600, RB300 and RB600.

As can be seen in Figure 1, a higher pyrolysis temperature enhances volatilization of organic compounds and formation of new porous structure that justifies increase in specific surface areas. EDS analyses (Figure 2) show that rice biochars compared to woody biochars contained more Si. Additionally, the rice biochars demonstrated $\mathrm{Al}$ peak which is because of high uptake of this element by rice, but in woody biochars, P peak was observed instead. These elements can be effective in $\mathrm{Zn}$ sorption by biochars.
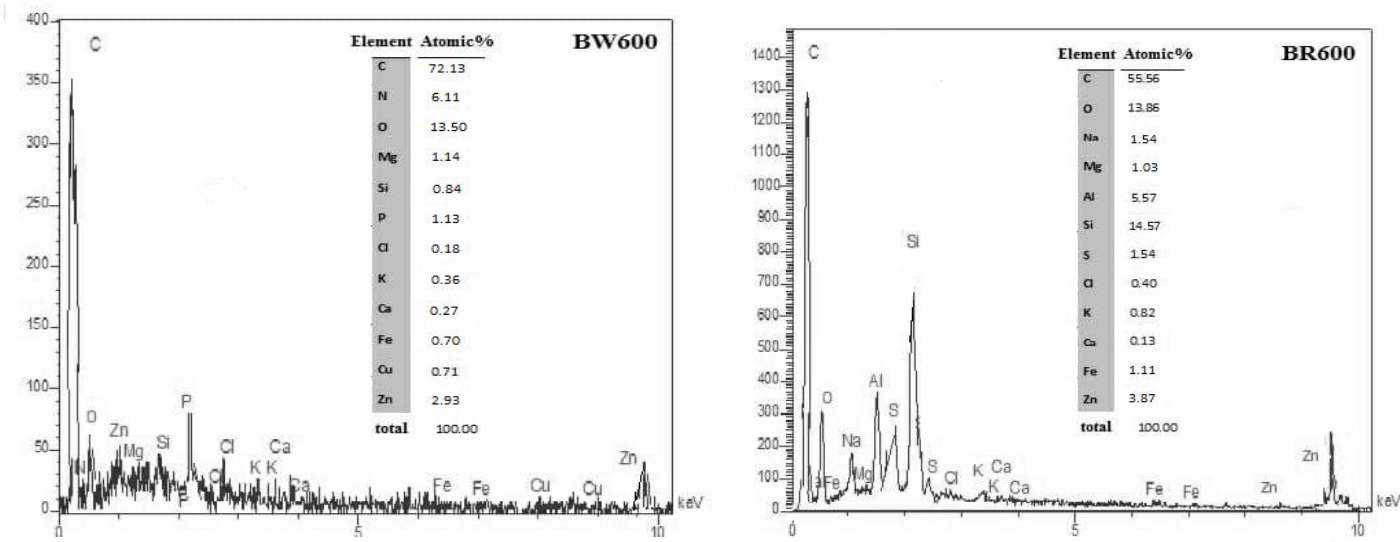

Figure 2. EDX spectra of WB600 and RB600 after Zn sorption, at initial Zn concentration of $200 \mathrm{mg} \mathrm{L}^{-1}$.

FTIR analysis of the biochars $\left(400-4000 \mathrm{~cm}^{-1}\right)$ at pre- and post-Zn sorption is shown in Figure 3. Usually as the pyrolysis temperature rises, complexities in FTIR peaks decrease. The band appears around $1100 \mathrm{~cm}^{-1}$ had a high intensity in rice biochars, while lower intensity was detected in woody biochars, chiefly limited to ether C-O-stretching vibrations. However, the peak declined after Zn sorption. Surface functional groups such as carboxyl and hydroxyl acting as protondonor or deprotonating agents involved in a covalent bond with $\mathrm{Zn}$ ions disappeared or lost their intensities (Samsuri et al., 2014). Stretching vibrations seen in the range of $2950 \mathrm{~cm}^{-1}$ are associated with $-\mathrm{CH}_{2}-/-\mathrm{CH}_{3}$ in aliphatics and alicyclies. This peak decreased or disappeared after Zn sorption on the studied biochars. Heavy metal bond with carbon (M-C bond) in these groups could be a metal-methylidin (MC), metal-methylin (MCH), or metal-methyl bonds depending upon the ligand attached to the carbon atom (Thirumavalavan et al., 2011). 
(a)

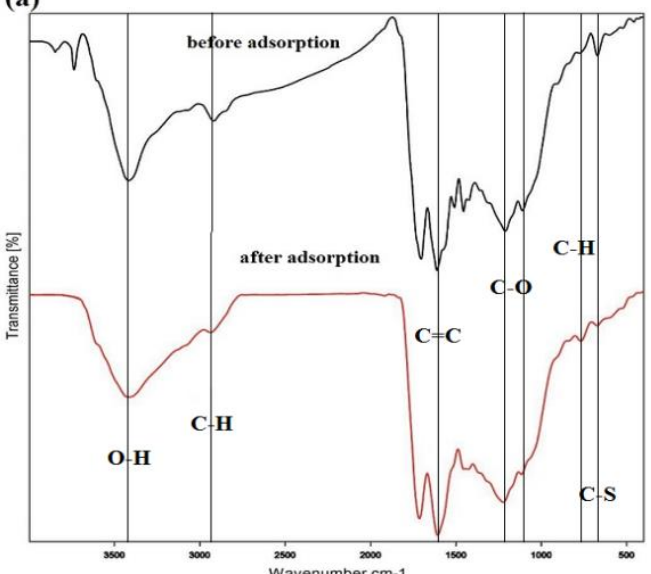

(c)

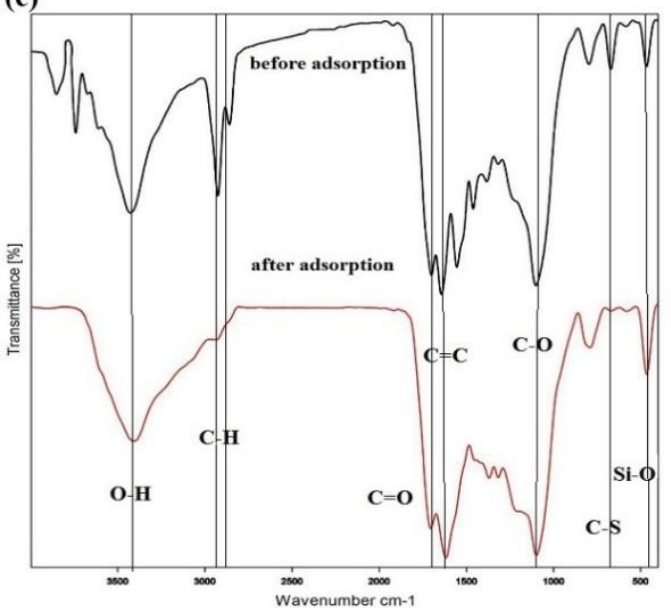

(b)

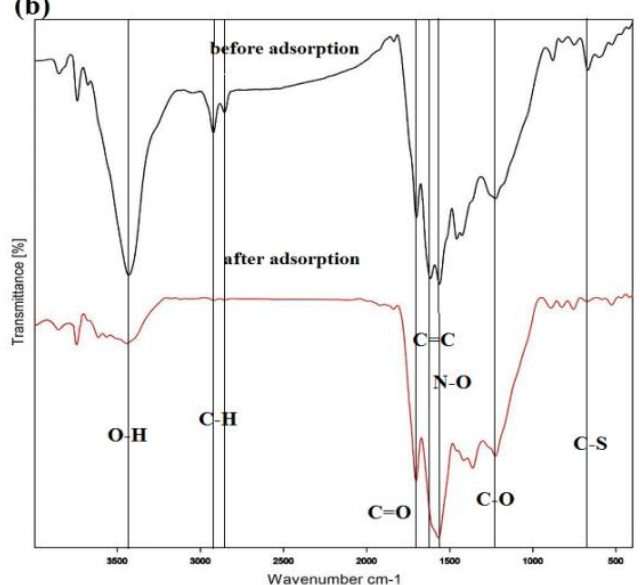

(d)

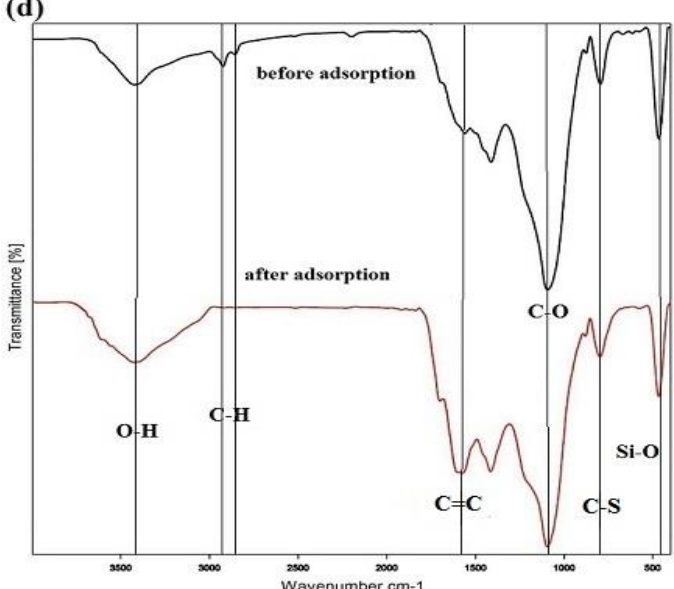

Figure 3. FTIR spectra of WB300, (a) WB600, (b) RB300, (c) and RB600 (d) before and after Zn sorption, at initial concentration of $200 \mathrm{mg} \mathrm{L}^{-1}$

\subsection{Kinetics of adsorption}

$\mathrm{Zn}$ adsorption on the studied biochars was a function of time and increased with time from 30 minutes to 24 hours (Figure 4). The sorption increased rapidly up to about 24 hours, beyond which a near steady-state condition was attained. Estimated $\mathrm{Zn}$ adsorption maxima were roughly 3.89, 16.32, 18.80 and $33.46 \mathrm{mg}$ g-1 in WB300, WB600, RB300 and RB600, respectively. The time spent to reach equilibrium state was shorter in WB300 than for other investigated biochars. Initial rapid adsorption is attributed to the surface adsorption of $\mathrm{Zn}$ ions on macropores and outer surfaces. These binding sites decreased with time and the adsorption entered the decelerated stage. Slow stage can be due to adsorption in micropores and the re-distribution of $\mathrm{Zn}$ ions from outer to inner surfaces (Ahmad et al., 2014; Betts et al., 2013).

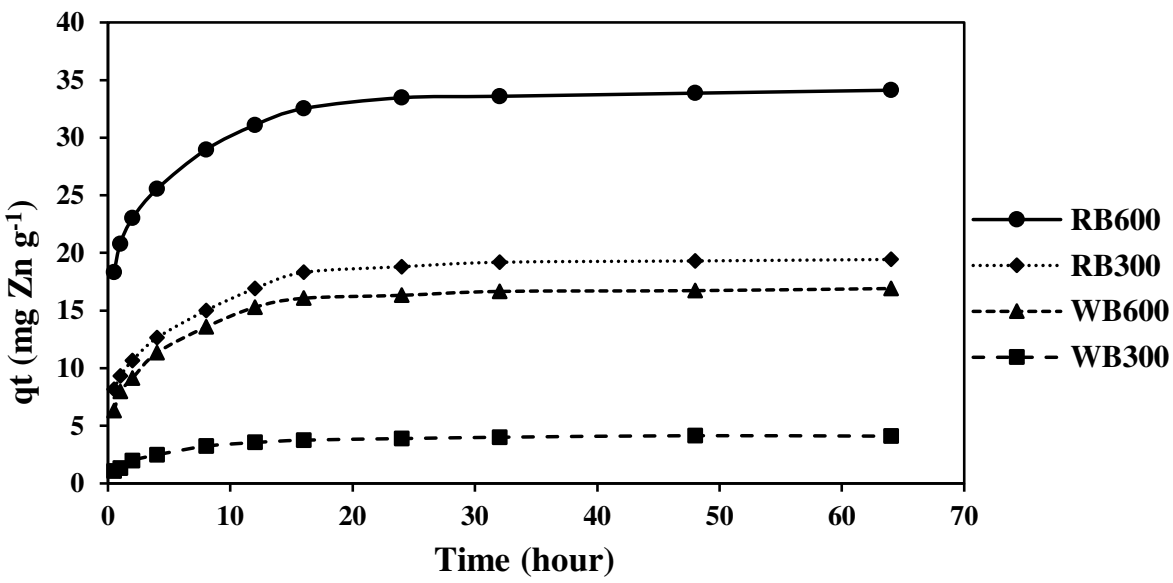

Figure 4. Adsorption kinetics of $\mathrm{Zn}$ by different biochars used in this study. 
According to the surface area values (Table 2) and the pore structure of the studied biochars (Figure 1), it can be claimed that $\mathrm{Zn}$ adsorption on WB300 occurs in outer surfaces and some macropores, whereas in the others, inner surfaces and micropores are also involved in Zn sorption. For times up to 64 hours, Zn sorption was the highest for RB600 and the lowest for WB300, while almost similar for RB300, WB600. Different equations were tested for their suitability to describe the kinetics of Zn sorption by the studied biochars. The range, mean $\mathrm{r}^{2}$ (coefficient of determination) and SEE (standard error of estimate) values appear in Table 3 . The results revealed that $\mathrm{r}^{2}$, in best fit equations follows the order Elovich > exponential > pseudo second-order > parabolic diffusion $>$ pseudo first-order. A look at the two models of Elovich and exponential proved to be more adequate in accounting for the process than the other models. Furthermore, it had highest $r^{2}$, and the least SEE. The average values of $r^{2}$ and SEE were $0.97,0.72$ for the Elovich model and 0.95 and 0.5 for the exponential model, respectively. Good fit of the Elovich model in Zn sorption on biochar derived from meat and bone meal have been previously reported (Betts et al., 2013). The constant " $\mathrm{a}$ ", that is a measure of the initial adsorption rate, for Elovich and exponential models for the four studied biochars was in an order of WB300 < WB600 < RB300 < RB600 (Table 4).

Table 3. Range and mean values of the coefficient of determination $\left(r^{2}\right)$ and standard error of estimate (SEE) for the kinetics models used in this study.

\begin{tabular}{|c|c|c|c|c|}
\hline \multirow{2}{*}{ Model } & \multicolumn{2}{|c|}{$\mathrm{r}^{2}$} & \multicolumn{2}{|c|}{ SEE } \\
\hline & Range & Mean & Range & Mean \\
\hline Pseudo-first order & $0.67-0.93$ & 0.80 & $0.35-3.48$ & 1.78 \\
\hline Pseudo-second order & $0.89-0.98$ & 0.93 & $11.93-50.83$ & 26.80 \\
\hline Parabolic diffusion & $0.78-0.83$ & 0.81 & $0.55-2.72$ & 1.78 \\
\hline Exponential & $0.93-0.96$ & 0.95 & $0.33-1.49$ & 1.05 \\
\hline Elovich & $0.97-0.98$ & 0.97 & $0.17-1.06$ & 0.72 \\
\hline
\end{tabular}

Since the Elovich model was developed on the basis of the chemical sorption on heterogeneous surfaces, one may argue that chemical bonds may have formed when $\mathrm{Zn}$ ions were adsorbed on heterogeneous surfaces of biochars. Elovich model addresses biphasic reactions in which the initial adsorption rate is high and then continues slowly, which has been observed in similar reactions and suggests a limited adsorption reaction by diffusion (Betts. et al., 2013). Cheung et al. (2000) described $\mathrm{Zn}$ and $\mathrm{Cu}$ sorption by biochar based on Elovich model inferring that adsorption rate is limited by diffusion via Biochar pores.

(a)

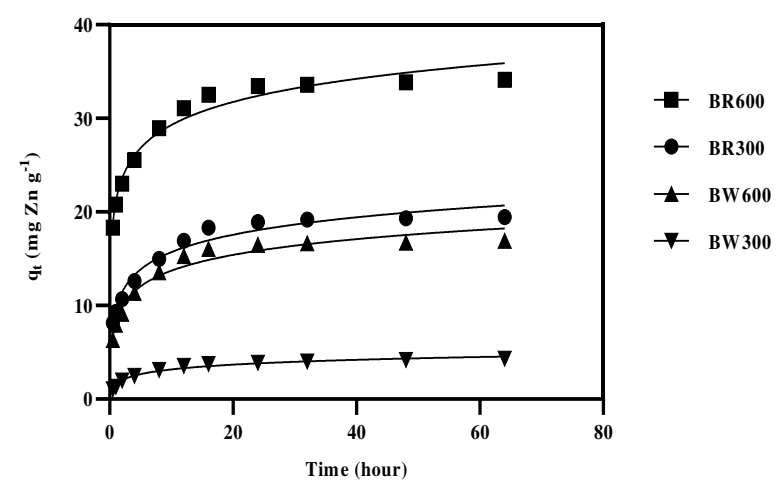

(b)

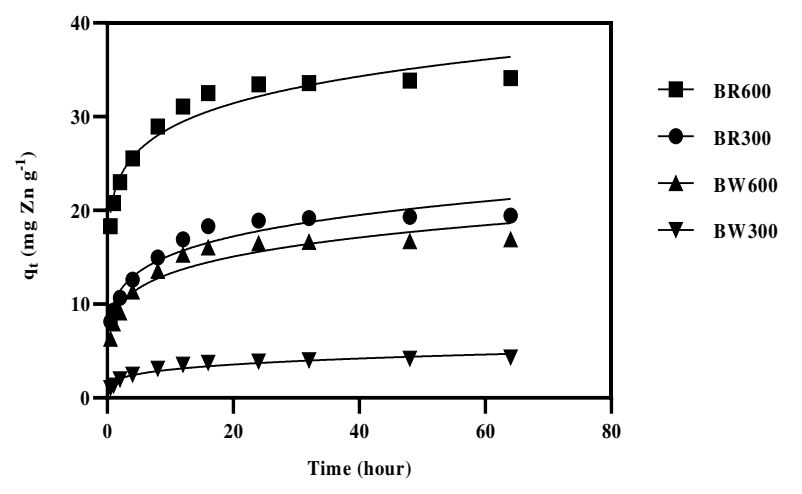

Figure 5. Zn sorption data for the studied biochars (a) the fitting of Elovich equation,(b) the fitting of exponential model. $\mathrm{q}_{\mathrm{t}}$ is the amount of $\mathrm{Zn}$ sorption $\left(\mathrm{mg} \mathrm{Zn} \mathrm{g}^{-1}\right)$ at time $\mathrm{t}$.

290 Table 4. Values of Elovich and exponential equation coefficients for $\mathrm{Zn}$ sorption by the studied biochars.

\begin{tabular}{|c|c|c|c|c|c|c|c|c|}
\hline \multirow[t]{2}{*}{ Biochar } & \multicolumn{4}{|c|}{ Elovich } & \multicolumn{4}{|c|}{ Exponential } \\
\hline & Ln $a$ & $\mathrm{~B}$ & $\mathrm{r}^{2}$ & SEE & $a$ & $\mathrm{~b}$ & $\mathrm{r}^{2}$ & SEE \\
\hline WB300 & 1.63 & 1.34 & 0.98 & 0.17 & 1.74 & 0.24 & 0.96 & 0.33 \\
\hline WB600 & 4.21 & 0.41 & 0.97 & 0.84 & 8.71 & 0.18 & 0.93 & 1.23 \\
\hline RB300 & 4.52 & 0.37 & 0.98 & 0.83 & 10.07 & 0.18 & 0.94 & 1.14 \\
\hline RB600 & 7.19 & 0.28 & 0.97 & 1.06 & 21.55 & 0.13 & 0.96 & 1.49 \\
\hline
\end{tabular}

Note: For units refer Table 1

\subsection{Adsorption isotherms}

Isotherm curves indicate that as the equilibrium concentration increases, $\mathrm{Zn}$ adsorption in biochars drops and the slope of the curve decreases which can be due to heterogeneous compounds in the sorption sites with different binding energy 
levels (Figure 6). Comparison of the shape of sorption isotherms in the studied biochars (Figure 6) showed the steep initial slope of $\mathrm{Zn}$ sorption isotherms for all biochars, especially for $\mathrm{RB} 600$, at all $\mathrm{pH}$ and ionic strength levels. This implies a high affinity for RB600 to adsorb Zn. Among the four studied biochars, RB600 showed the highest pH can increase the negative surface charge through the deprotonation of hydroxyl and carboxyl groups would lead to increase $\mathrm{Zn}$ sorption. On the other hand, earth alkaline metals $(\mathrm{Ca}$ and $\mathrm{Mg}$ ) originated from R-O-M and R-COO-M surface functional groups in RB600 enter cation exchange reaction thereby raising biochar's Zn sorption capacity (Zhao et al., 2020). With increasing the ionic strength of solution, $\mathrm{Zn}$ adsorption by four biochars decreased at all $\mathrm{pH}$ levels and the lowest $\mathrm{Zn}$ sorption amount was for WB300.
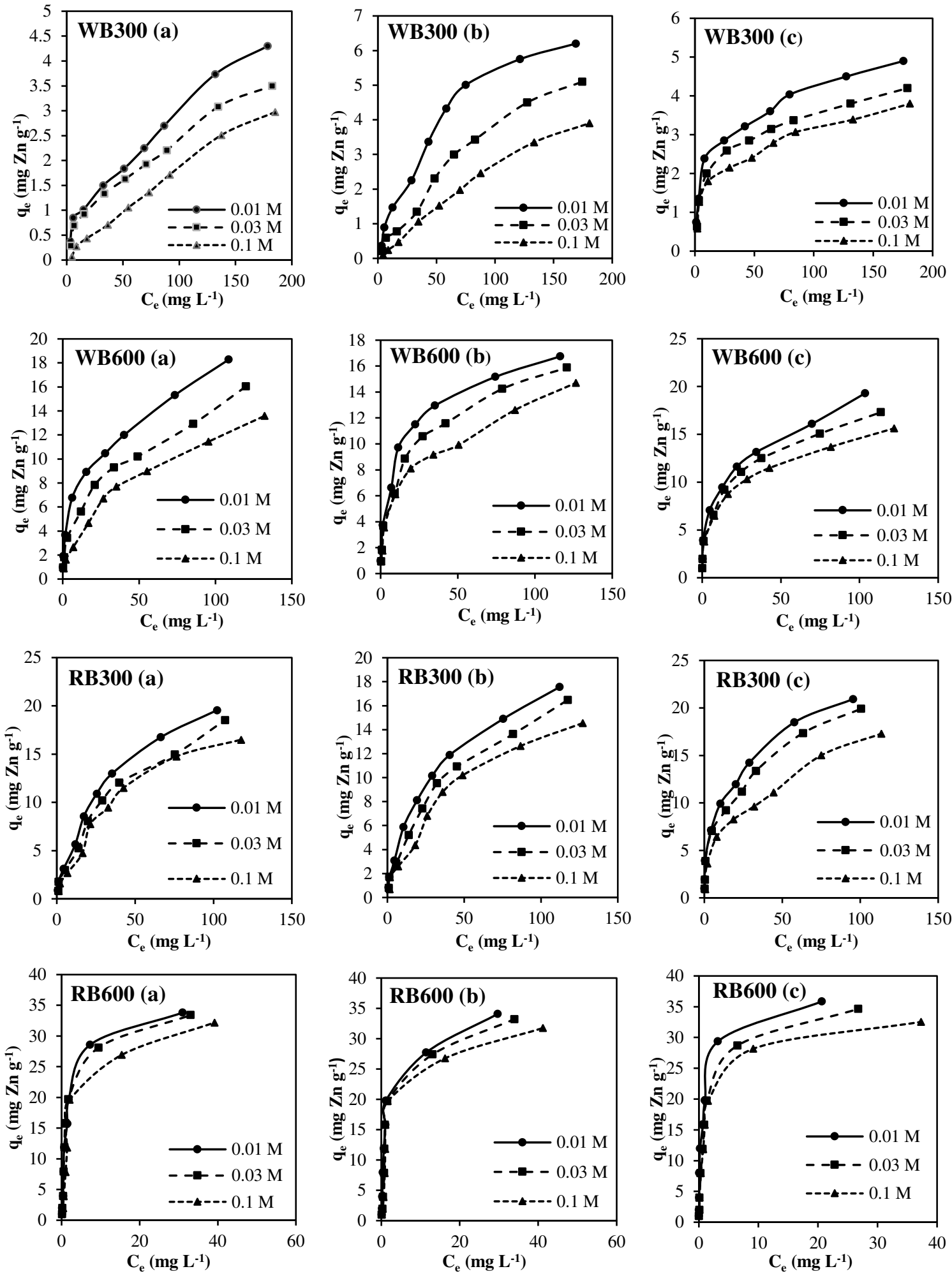

Figure 6. Zn sorption isotherm data for WB300, WB600, RB300 and RB600 in (a) Unadjusted pH, (b) pH adjusted to 4 and (c) $\mathrm{pH}$ adjusted to 6 
In this study, Freundlich, Langmuir and Dubinin-Radushkevich models were applied to simulate Zn sorption on the studied biochars with a good fit. The parameters $\mathrm{r}^{2}$, and SEE of these models are presented in Tables 5-8. Results indicated that the Freundlich and Dubinin-Radushkevich models are slightly better than Langmuir model for BW300, BW600 and BR300 with regard to $\mathrm{r}^{2}$ and SEE values. The reason for the better fit of Freundlich model, aside from the empirical nature, can be the involvement of various mechanisms in the process of multi-layered, heterogeneous and surface adsorption. Better fitting of Freundlich model to the adsorption data in biochars derived from Scots pine wood and silver birch wood (derived at 450 and $750^{\circ} \mathrm{C}$ ) (Mubarak et al, 2013) and biochars derived from sugar cane bagasse, eucalyptus forest residues, and castrol meal have been reported in the literature (Doumer et al., 2016).

As with RB600, Langmuir model provided a better fit than the other two isotherms indicating that $\mathrm{Zn}$ sorption on this biochar probably occurred in the absence of significant interaction among the adsorbed molecules or adsorbing sites with almost equal energy (Park et al., 2016). Some scholars believed that a better fitting of Langmuir's model suggests the presence of chemisorption process (Kizito et al., 2015). Jiang et al. (2016) stated that the biochars produced at high pyrolysis temperatures $\left(>500^{\circ} \mathrm{C}\right)$ have a high degree of carbon crystallites because turbostatic crystallites develop, which may explain why Langmuir provides a better fit for these biochars. Studies report that heavy metal adsorption by biochar often occurs through ionic exchange and surface complexation between biochar functional groups and metal ions (Oliveira et al., 2017). Cation $\pi$ bond plays a crucial role in heavy metal sorption by biochars prepared at high pyrolysis temperatures, which is in turn attributable to graphitic structures.

Results in Tables 5-8 show that high pyrolysis temperatures correlated with a rise in $\mathrm{K}_{\mathrm{F}}$ as an adsorption capacity index. Maximum and minimum $\mathrm{K}_{\mathrm{F}}$ values were observed in RB600 and WB300, respectively. The highest adsorption intensity was observed at $\mathrm{pH}$ adjusted to 6 . Also, when the ionic strength of the solution increased, $\mathrm{Zn}$ adsorption intensity decreased. In the studied biochars, $\mathrm{n}$ values in Freundlich model were larger than 1, which suggests different energy levels of the $\mathrm{Zn}$ adsorbing surfaces.

Table 5. Freundlich, Langmuir and Dubinin-radushkevich isotherm constants for the adsorption of Zn on WB300 at different $\mathrm{pH}$ and ionic strength values.

\begin{tabular}{ccccccccccccc}
\hline \multirow{2}{*}{$\mathrm{pH}$} & \multirow{2}{*}{$\mathrm{I} . \mathrm{S}$} & \multirow{2}{*}{$\mathrm{q}_{\exp 200}$} & \multicolumn{3}{c}{ Langmuir } & \multicolumn{3}{c}{ Freundlich } & \multicolumn{3}{c}{ Dubinin-Radushkevich } \\
\cline { 3 - 12 } & & $\mathrm{K}_{\mathrm{L}}\left(.10^{-2}\right)$ & $\mathrm{q}_{\mathrm{m}}$ & $\mathrm{r}^{2}$ & $\mathrm{~K}_{\mathrm{F}}$ & $\mathrm{n}$ & $\mathrm{r}^{2}$ & $\mathrm{~K}_{\mathrm{D}}\left(.10^{-3}\right)$ & $\mathrm{q}_{\mathrm{m}}{ }^{\prime}$ & $\mathrm{E}$ & $\mathrm{r}^{2}$ \\
\hline \multirow{3}{*}{ N.A } & 0.01 & 4.3 & 1.2 & 5.87 & 0.96 & 0.23 & 1.83 & 0.99 & 6.1 & 15.04 & 9.05 & 0.98 \\
& 0.03 & 3.5 & 0.9 & 5.54 & 0.96 & 0.17 & 1.74 & 0.99 & 6.3 & 13.08 & 8.91 & 0.98 \\
& 0.1 & 2.9 & 0.4 & 5.47 & 0.96 & 0.06 & 1.38 & 0.99 & 8.1 & 13.02 & 7.85 & 0.99 \\
\hline \multirow{3}{*}{4} & 0.01 & 6.2 & 1.5 & 8.87 & 0.99 & 0.44 & 1.88 & 0.96 & 6.2 & 25.04 & 8.98 & 0.98 \\
& 0.03 & 5.1 & 0.7 & 8.54 & 0.99 & 0.17 & 1.53 & 0.97 & 8.3 & 25.50 & 7.76 & 0.98 \\
& 0.1 & 3.9 & 0.5 & 7.66 & 0.99 & 0.08 & 1.37 & 0.98 & 8.2 & 23.55 & 7.81 & 0.99 \\
\hline \multirow{2}{*}{6} & 0.01 & 4.9 & 9.2 & 4.59 & 0.95 & 1.05 & 3.31 & 0.97 & 3.4 & 9.81 & 12.13 & 0.98 \\
& 0.03 & 4.2 & 7.4 & 4.25 & 0.93 & 0.81 & 3.02 & 0.98 & 3.5 & 9.30 & 11.95 & 0.98 \\
& 0.1 & 3.8 & 5.1 & 3.93 & 0.92 & 0.67 & 2.88 & 0.98 & 3.7 & 8.63 & 11.62 & 0.97 \\
\hline
\end{tabular}

I.S: ionic strength, N.A: unadjusted $\mathrm{pH}, \mathrm{q}_{\text {exp200: }}$ the maximum experimental amount of adsorbed $\mathrm{Zn}$ at equilibrium concentration $\left(\mathrm{mg} \mathrm{g}^{-1}\right) \mathrm{q}_{\mathrm{m}}$ and $\mathrm{q}_{\mathrm{m}}$ : : maximum adsorption capacity $\left(\mathrm{mg} \mathrm{g}^{-1}\right), \mathrm{K}_{\mathrm{D}}$ : constant related to the adsorption energy $\left(\mathrm{mol}^{2} \mathrm{~kJ}^{-2}\right)$, E: sorption energy $\left(\mathrm{kJ} \mathrm{mol}^{-1}\right)$.

Table 6. Freundlich, Langmuir and Dubinin-radushkevich isotherm constants for the adsorption of Zn on WB600 at different $\mathrm{pH}$ and ionic strength values.

\begin{tabular}{cccccccccccccc}
\hline \multirow{2}{*}{$\mathrm{pH}$} & \multirow{2}{*}{$\mathrm{I} . \mathrm{S}$} & $\mathrm{q}_{\text {exp200 }}$ & \multicolumn{2}{c}{ Langmuir } & \multicolumn{4}{c}{ Freundlich } & \multicolumn{3}{c}{ Dubinin-Radushkevich } \\
\cline { 3 - 13 } & & & $\mathrm{K}_{\mathrm{L}}\left(.10^{-2}\right)$ & $\mathrm{q}_{\mathrm{m}}$ & $\mathrm{r}^{2}$ & $\mathrm{~K}_{\mathrm{F}}$ & $\mathrm{n}$ & $\mathrm{r}^{2}$ & $\mathrm{~K}_{\mathrm{D}}\left(.10^{-3}\right)$ & $\mathrm{q}_{\mathrm{m}}{ }^{\prime}$ & $\mathrm{E}$ & $\mathrm{r}^{2}$ \\
\hline \multirow{2}{*}{ N.A } & 0.01 & 18.27 & 5.9 & 19.04 & 0.94 & 2.99 & 2.61 & 0.99 & 3.8 & 45.58 & 11.47 & 0.99 \\
& 0.03 & 16.03 & 3.6 & 18.17 & 0.95 & 2.01 & 2.34 & 0.99 & 4.4 & 44.47 & 10.66 & 0.99 \\
& 0.1 & 13.58 & 2.2 & 17.38 & 0.98 & 1.23 & 2.03 & 0.99 & 5.4 & 45.78 & 9.62 & 0.99 \\
\hline \multirow{3}{*}{4} & 0.01 & 16.74 & 10.3 & 17.26 & 0.98 & 3.79 & 3.08 & 0.97 & 3.2 & 38.19 & 12.46 & 0.99 \\
& 0.03 & 15.87 & 7.7 & 16.88 & 0.97 & 2.93 & 2.76 & 0.98 & 3.6 & 37.16 & 11.70 & 0.99 \\
& 0.1 & 14.70 & 6.2 & 14.79 & 0.95 & 2.40 & 2.67 & 0.98 & 3.8 & 35.51 & 11.47 & 0.99 \\
\hline \multirow{2}{*}{6} & 0.01 & 19.29 & 8.5 & 19.17 & 0.93 & 4.25 & 3.12 & 0.99 & 3.1 & 40.35 & 12.70 & 0.99 \\
& 0.03 & 17.29 & 7.3 & 18.10 & 0.95 & 3.85 & 3.13 & 0.99 & 3.1 & 37.12 & 12.70 & 0.99 \\
& 0.1 & 15.62 & 8.1 & 15.79 & 0.95 & 3.53 & 3.21 & 0.99 & 3.0 & 32.37 & 12.90 & 0.99 \\
\hline
\end{tabular}


Table 7. Freundlich, Langmuir and Dubinin-radushkevich isotherm constants for the adsorption of Zn on RB300 at different $\mathrm{pH}$ and ionic strength values.

\begin{tabular}{ccccccccccccc}
\hline \multirow{2}{*}{$\mathrm{pH}$} & \multirow{2}{*}{$\mathrm{I} . \mathrm{S}$} & \multirow{2}{*}{$\mathrm{q}_{\text {exp200 }}$} & \multicolumn{3}{c}{ Langmuir } & \multicolumn{4}{c}{ Freundlich } & \multicolumn{3}{c}{ Dubinin-Radushkevich } \\
\cline { 3 - 13 } & & & $\mathrm{K}_{\mathrm{L}}\left(.10^{-2}\right)$ & $\mathrm{q}_{\mathrm{m}}$ & $\mathrm{r}^{2}$ & $\mathrm{~K}_{\mathrm{F}}$ & $\mathrm{n}$ & $\mathrm{r}^{2}$ & $\mathrm{~K}_{\mathrm{D}}\left(.10^{-3}\right)$ & $\mathrm{q}_{\mathrm{m}}{ }^{\prime}$ & $\mathrm{E}$ & $\mathrm{r}^{2}$ \\
\hline \multirow{3}{*}{ N.A } & 0.01 & 19.54 & 3.1 & 25.79 & 0.99 & 1.91 & 1.95 & 0.98 & 5.4 & 78.48 & 9.62 & 0.99 \\
& 0.03 & 18.52 & 2.6 & 25.37 & 0.98 & 1.45 & 1.84 & 0.99 & 5.8 & 71.94 & 9.28 & 0.99 \\
& 0.1 & 16.48 & 2.2 & 23.89 & 0.99 & 1.33 & 1.84 & 0.97 & 5.9 & 71.94 & 9.20 & 0.98 \\
\hline \multirow{3}{*}{4} & 0.01 & 17.56 & 3.3 & 21.81 & 0.99 & 1.88 & 2.08 & 0.99 & 5.0 & 62.78 & 10.00 & 0.99 \\
& 0.03 & 16.48 & 2.5 & 21.85 & 0.99 & 1.45 & 1.95 & 0.99 & 5.5 & 63.43 & 9.53 & 0.99 \\
& 0.1 & 14.55 & 2.4 & 20.56 & 0.99 & 1.16 & 1.88 & 0.98 & 5.8 & 60.82 & 9.28 & 0.98 \\
\hline \multirow{2}{*}{6} & 0.01 & 20.92 & 7.1 & 22.77 & 0.94 & 4.44 & 2.91 & 0.99 & 3.3 & 49.05 & 12.30 & 0.99 \\
& 0.03 & 19.90 & 6.5 & 22.12 & 0.93 & 3.84 & 3.13 & 0.99 & 3.7 & 50.08 & 11.62 & 0.99 \\
& 0.1 & 17.28 & 4.9 & 19.62 & 0.94 & 2.44 & 2.42 & 0.99 & 4.2 & 47.08 & 10.91 & 0.98 \\
\hline
\end{tabular}

Table 8. Freundlich, Langmuir and Dubinin-radushkevich isotherm constants for the adsorption of $\mathrm{Zn}$ on RB600 at different $\mathrm{pH}$ and ionic strength values.

\begin{tabular}{|c|c|c|c|c|c|c|c|c|c|c|c|c|}
\hline \multirow{2}{*}{$\mathrm{pH}$} & \multirow{2}{*}{ I.S } & \multirow[b]{2}{*}{$\mathrm{q}_{\exp 200}$} & \multicolumn{3}{|c|}{ Langmuir } & \multicolumn{3}{|c|}{ Freundlich } & \multicolumn{4}{|c|}{ Dubinin-Radushkevich } \\
\hline & & & $\mathrm{K}_{\mathrm{L}}\left(.10^{-2}\right)$ & $\mathrm{q}_{\mathrm{m}}$ & $\mathrm{r}^{2}$ & $\mathrm{~K}_{\mathrm{F}}$ & $\mathrm{n}$ & $\mathrm{r}^{2}$ & $\mathrm{~K}_{\mathrm{D}}\left(.10^{-3}\right)$ & $\mathrm{q}_{\mathrm{m}}^{\prime}$ & $\mathrm{E}$ & $r^{2}$ \\
\hline \multirow{3}{*}{ N.A } & 0.01 & 33.80 & 59 & 35.68 & 0.99 & 11.98 & 3.02 & 0.87 & 2.8 & 102.1 & 13.36 & 0.92 \\
\hline & 0.03 & 33.39 & 69 & 34.26 & 0.97 & 11.84 & 3.10 & 0.86 & 2.7 & 94.83 & 13.60 & 0.91 \\
\hline & 0.1 & 32.17 & 46 & 33.25 & 0.93 & 10.13 & 2.93 & 0.86 & 2.9 & 92.86 & 13.13 & 0.89 \\
\hline \multirow{3}{*}{4} & 0.01 & 34.07 & 87 & 33.54 & 0.97 & 12.29 & 3.14 & 0.88 & 2.6 & 92.21 & 13.86 & 0.93 \\
\hline & 0.03 & 32.21 & 62 & 33.55 & 0.94 & 11.04 & 3.02 & 0.85 & 2.8 & 92.86 & 13.36 & 0.90 \\
\hline & 0.1 & 31.75 & 56 & 32.13 & 0.92 & 10.37 & 3.14 & 0.82 & 2.7 & 84.36 & 13.60 & 0.88 \\
\hline \multirow{3}{*}{6} & 0.01 & 35.86 & 156 & 35.49 & 0.96 & 16.93 & 3.60 & 0.92 & 2.2 & 91.56 & 15.07 & 0.96 \\
\hline & 0.03 & 34.64 & 87 & 35.28 & 0.99 & 13.84 & 3.27 & 0.92 & 2.4 & 94.83 & 14.43 & 0.96 \\
\hline & 0.1 & 32.53 & 88 & 32.80 & 0.99 & 13.05 & 3.58 & 0.91 & 2.3 & 78.48 & 14.71 & 0.95 \\
\hline
\end{tabular}

Comparing the experimental ( $\left.\mathrm{q}_{\mathrm{exp} 200}\right)$ and Langmuir adsorption maxima $\left(\mathrm{q}_{\mathrm{m}}\right)$ in WB300 indicated that " $\mathrm{q}_{\exp 200 "}$ " at three ionic strengths used, unadjusted $\mathrm{pH}$ and adjusted $\mathrm{pH} 4$ were lower than Langmuir " $\mathrm{q}_{\mathrm{m}}$ "; however, their values were almost equal for adjusted pH at 6 (Table 5). In the case of WB600 and RB600 the Langmuir " $\mathrm{q}_{\mathrm{m}}$ " value at unadjusted and adjusted pH 4 were larger than "qexp200", but did not differ much at pH 6 (Table 6 and 7). In RB300, "qm" exceeded "qexp200" at all $\mathrm{pH}$ and ionic strength values (Table 8). Close proximity of " $\mathrm{q}_{\text {exp200" }}$ " and Langmuir " $\mathrm{q}_{\mathrm{m}}$ " in studied biochars suggests

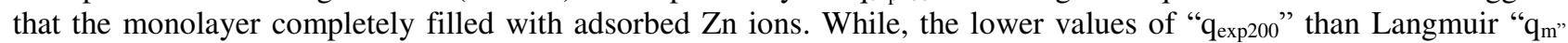
indicates that the adsorption monolayer is not filled yet. Jiang et al., (2016) reported a higher " $\mathrm{q}_{\mathrm{m}}$ " in hard (jarrah) wood biochar $\left(2.33 \mathrm{mg} \mathrm{g}^{-1}\right)$ than soft (pine) wood biochar $\left(1 \mathrm{mg} \mathrm{g}^{-1}\right)$ regarding $\mathrm{Zn}$ sorption. Comparing Langmuir sorption affinity $\left(\mathrm{K}_{\mathrm{L}}\right)$ in biochars demonstrated that RB600 contained highest $\mathrm{K}_{\mathrm{L}}$, while lowest occurred in WB300. The other two biochars were almost the same regarding this parameter. Such a difference is undoubtedly associated with dissimilar physicochemical properties of the biochars (Table 2). In rice biochars, $\mathrm{pH}, \mathrm{CEC}$ and $\mathrm{pH}_{\mathrm{pzc}}$ were more than in woody biochars. Moreover, compared to the latter, they contained more oxygen-containing functional groups. This is the reason for higher $\mathrm{Zn}$ adsorption capacity of rice biochars (Li et al., 2017). Such an effect was also evident in FTIR results (Figure 3 ). Another factor is higher $\mathrm{P}$ and $\mathrm{N}$ concentrations in these biochars than woody biochars (Table 2), because of high complexation constants (pK) of heavy metals with groups containing P and N (Bogusz, et al., 2019). High Si concentration, too, has a part to play in increasing adsorption capacity (Figure 2, 3).

Dubinin-Radushkevich model assumes an association between the sorption and filling the micropore volumes and seems to be better than Langmuir model in that it doesn't consider adsorption exclusively depending on a homogeneous surface with a constant adsorption potential. The highest $\mathrm{K}_{\mathrm{D}}$ value was observed in WB300 (Table 5) in which $\mathrm{K}_{\mathrm{D}}$ in adjusted $\mathrm{pH}$ 4 was more than in any other states which is well-supported by WB300's sigmoid curve (Figure 6). As the $K_{D}$ dropped, the isotherms curves lost their sigmoidal shapes. Table 8 shows that the lowest $\mathrm{K}_{\mathrm{D}}$ in RB600 is evident and H-shaped isotherms in this type support the high sorption affinity in RB600 (Hu and Zhang, 2019). Mean free energy (E) was lower than 8 only in WB300 indicating physical adsorption. Other biochars with E $>8$ showed that Zn could be adsorbed chemically.

Physical adsorption depends on the surface characteristics such as pore structure, and according to Zhang et al. (2020) is not a significant mechanism in the case of heavy metals sorption.

\subsubsection{Effects of Initial $\mathrm{pH}$ and ionic Strength}

Initial $\mathrm{pH}$ of the solution is one of the most vital parameters in heavy metal sorption process since by influencing the quantity of surface charge and metal precipitation in the solution, a lot of variation in adsorption capacity and metal removal efficiency would result. Figure 7 clearly illustrates that the highest amount of Zn removal from solution occurred at pH 6 in WB600, RB300, and RB600. However, in WB300 the highest percentage of removal was observed at pH 4. 
The more acidity of the solution, the more $\mathrm{H}^{+}$ion competition with $\mathrm{Zn}$ ions is expected to occur which keeps them away from adsorbing sites.

In order to examine the effect of $\mathrm{Zn}$ sorption on solution $\mathrm{pH}$, equilibrium $\mathrm{pH}$ (at post-adsorption stage) in all studied biochars with four initial concentrations (Ci) $\left(5,40,100,200 \mathrm{mg} \mathrm{L}^{-1)}\right.$ was measured. Results indicated that in the initial $\mathrm{pH}$ adjusted at 4, the solution $\mathrm{pH}$ values rose in all biochars following $\mathrm{Zn}$ sorption but in adjusted $\mathrm{pH}$ at 6 , the trend of $\mathrm{pH}$ changes were not similar for all biochars. In the case of WB300 in all initial concentrations, pH dropped below 6 after Zn sorption. While in RB600 after Zn sorption was complete, pH exceeded 6. In WB600 and RB300 in low initial concentrations $\mathrm{pH}$ increased, but a decrease in $\mathrm{pH}$ after $\mathrm{Zn}$ sorption was observed in high initial concentrations. In Figure 7 , Zn removal efficiency in all $\mathrm{pH}$ values and ionic strengths investigated in $\mathrm{C}_{\mathrm{i}}=200 \mathrm{mg} \mathrm{L}^{-1}$ are presented. As it is shown in the Figure, except for WB300 that offers the highest efficiency for $\mathrm{Zn}$ removal at adjusted $\mathrm{pH} 4$, the other three biochars demonstrated the same efficiency at $\mathrm{pH} 6$.
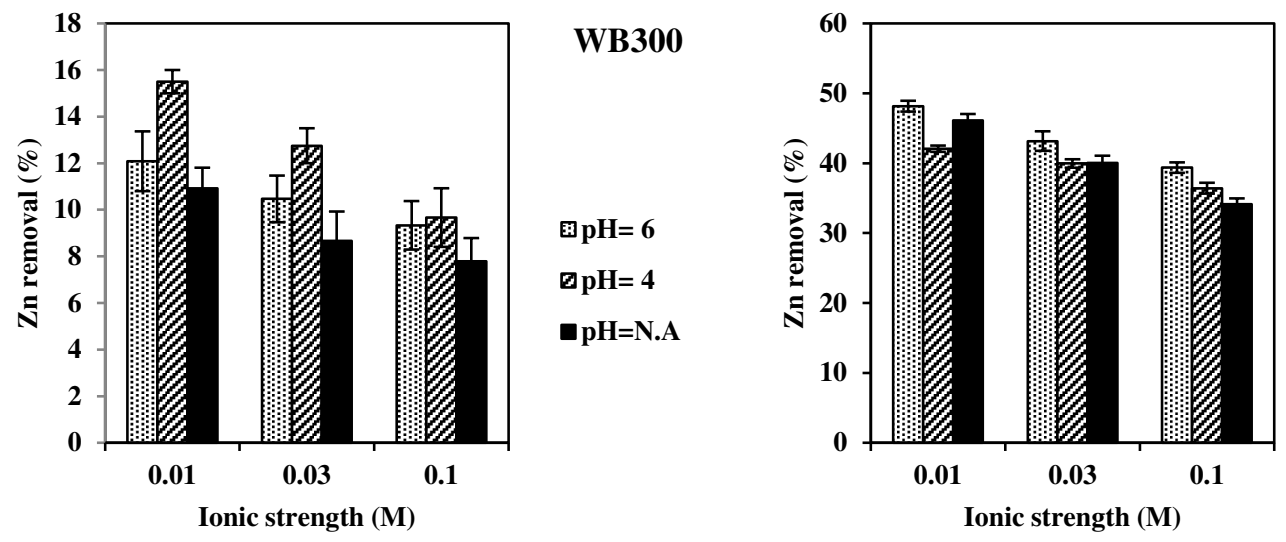

\section{WB600}
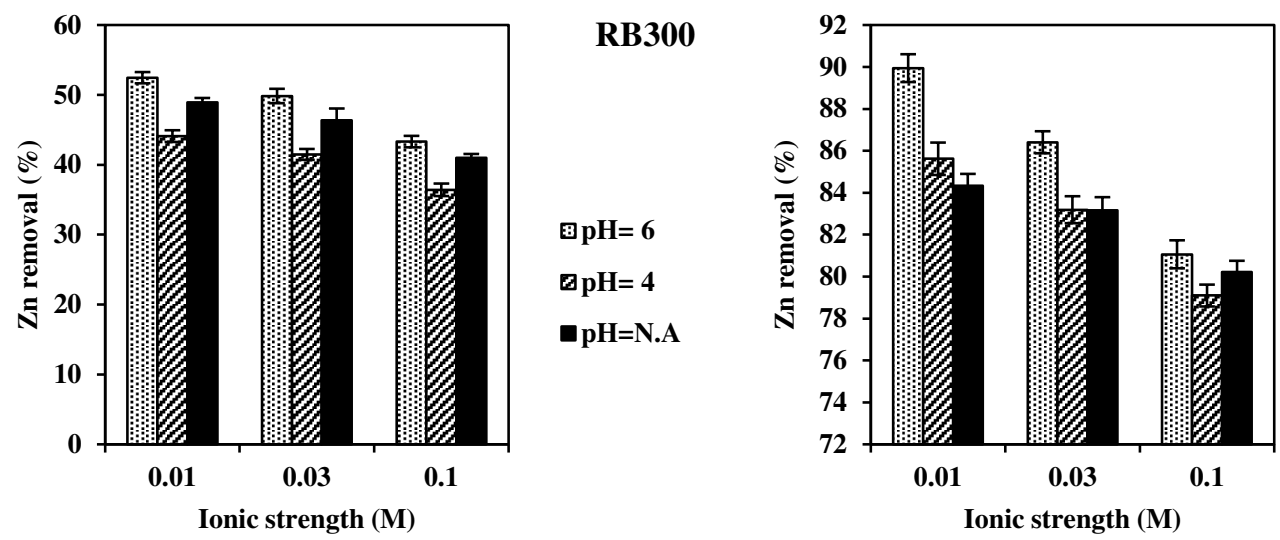

RB600

Figure 7. Zn removal in studied biochars at highest initial concentration $\left(200 \mathrm{mg} \mathrm{L}^{-1}\right)$

In rice based biochars, compared to woody biochars, higher $\mathrm{O}$ and oxygen-containing groups were found and $\mathrm{O} / \mathrm{C}$ ratio in rice biochars was higher (Table 2). Oxygen-containing groups play a crucial role in sorption of metal ions are more prone to complexation with metals (Li et al., 2017). Another effective factor in different quantities of heavy metal sorption by biochars is different concentration of sulfur $(\mathrm{S})$, phosphorous $(\mathrm{P})$, and nitrogen $(\mathrm{N})$ they contain. The $\mathrm{N}$ concentration in rice based biochars were similar to woody biochars but P concentration in WB600, WB300, RB600 and RB300 corresponded with the adsorption order for $\mathrm{Zn}$ in these biochars, which accounts for $\mathrm{Zn}$ complexation with P-containing group. FTIR spectra confirm the presence of S groups in all derived biochars. Decrease in peak intensities following $\mathrm{Zn}$ sorption can be justified by $\mathrm{Zn}$ complexation with S-containing groups. Additionally, the presence of silicon $(\mathrm{Si})$ in rice biochars can mean that biochars have a higher adsorption capacity (Figure 3) (Bogusz et al., 2019).

In this study, the highest $\mathrm{Zn}$ removal efficiency for all of the studied biochars and $\mathrm{pH}$ levels was observed at $0.01 \mathrm{M}$ ionic strength, while the lowest was recorded at $0.1 \mathrm{M}$ ionic strength (Figure 7). As the ionic strength increased, solution $\mathrm{K}^{+}$ concentration increased such that these ions were accumulated in the vicinity of biochar surface. The close correspondence between $\mathrm{K}^{+}$ions and the surfaces can decrease interactions between $\mathrm{Zn}$ ions and active sites and led to reduction in $\mathrm{Zn}$ removal. Moreover, boosted ionic strengths tend to motivate $\mathrm{K}$ and $\mathrm{Zn}$ ionic competition; therefore, $\mathrm{K}$ ions are deposited on active adsorption sites. In this way, $\mathrm{Zn}$ adsorption capacity and removal efficiency of $\mathrm{Zn}$ diminishes (Salmani et al., 2013). Wang et al. (2015) reported that with increasing solution ionic strength from $0.01 \mathrm{M}$ to $0.1 \mathrm{M}$, the removal rate of $\mathrm{Cu}, \mathrm{Cd}$, and $\mathrm{Pb}$ in pristine and engineered wood biochars decreased. 
414 Desorption experiments were performed at all three ionic strengths $(0.01,0.03$ and $0.1 \mathrm{M})$.

(b)

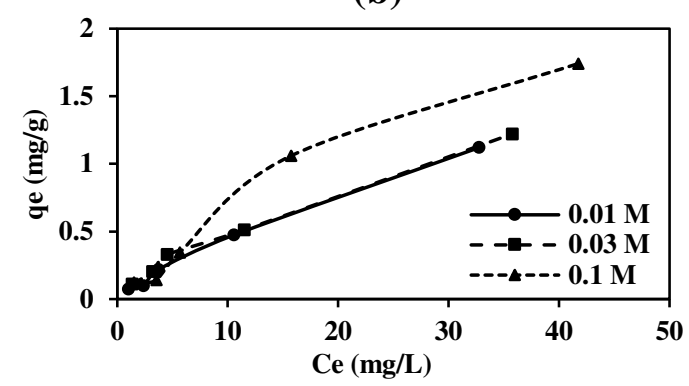

(c)

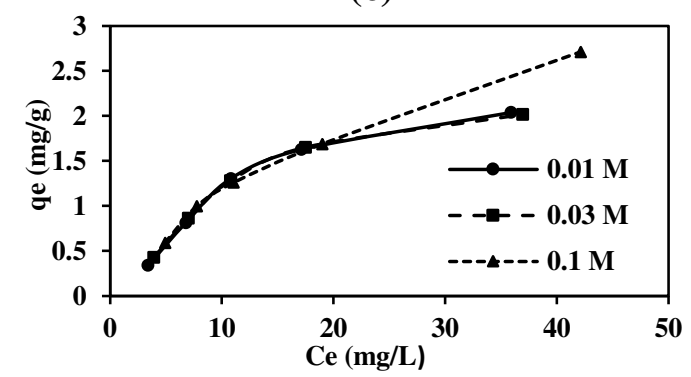

(a)

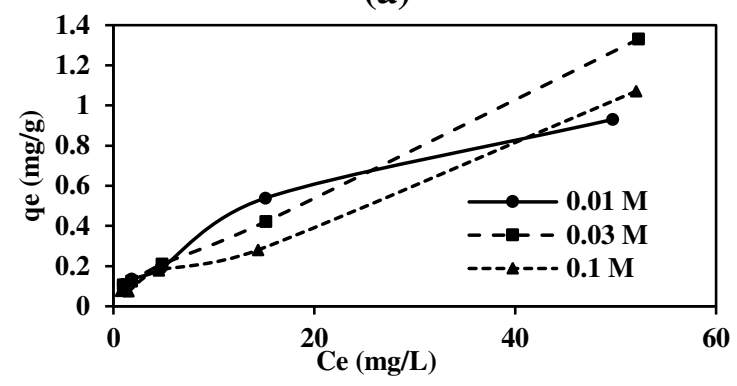

(d)

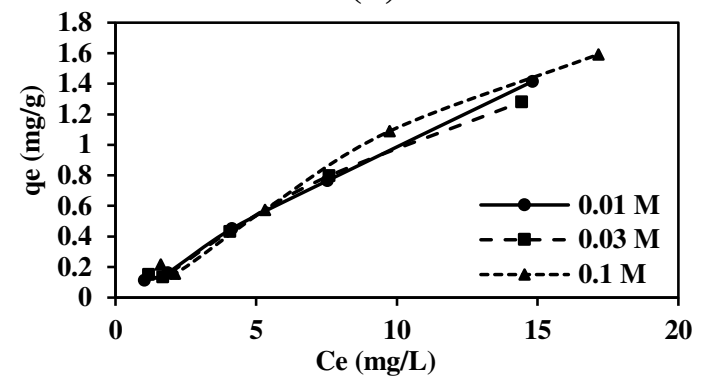

Figure 8. Zn desorption isotherms for studied biochars, WB300 (a), WB600 (b), RB300 (c), RB600 (d)

418 In this study, the maximum desorption was observed in WB300; however, RB600 was found to possess a good capability 419 for adsorption and retention of $\mathrm{Zn}$. After five steps of desorption, on average of 57.0, 16.1, 35.6 and 9.5 percentage of adsorbed Zn were desorbed in solution in WB300, WB600, RB300 and RB600, respectively.

According to Figure 8, the amount of desorbed $\mathrm{Zn}$ from WB300, RB300 and RB6OO at $0.1 \mathrm{M}$ ionic strength was higher than that in the two other ionic strengths. $\mathrm{Zn}$ desorption showed no change at 0.01 and $0.03 \mathrm{M}$ ionic strengths (Figure 8). Since in the present research, $\mathrm{Zn}$ desorption experiments occurred at natural $\mathrm{pH}$ levels, it is estimated that low desorption may have been due to $\mathrm{pH}$ differences in RB600 compared to WB300 (that is $\mathrm{pH} 9.6$ compared to $\mathrm{pH} 5.3$, respectively) (Bogusz et al., 2015). On the other hand, Zn sorption on WB300 may have occurred on external surfaces and macropores and bar the possibility of diffusion to micropores and internal surfaces which may be yet another reason for easy $\mathrm{Zn}$ desorption in this biochar. 

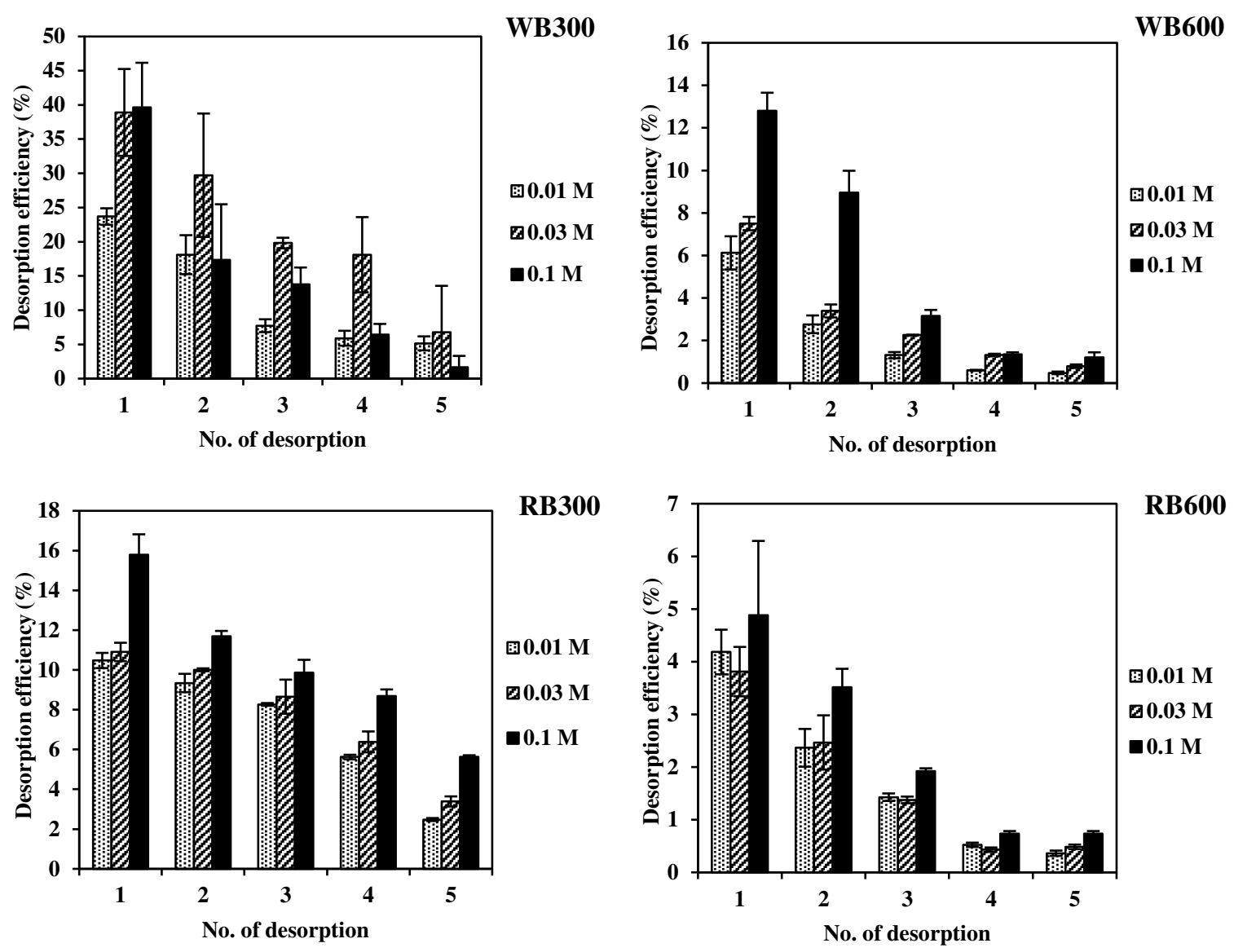

442 Figure 9. Zinc desorption efficiency of studied biochars in five steps of desorption

Figure 9 indicates that $\mathrm{Zn}$ desorption efficiency in biochars were higher at the first steps of experiments. Comparing biochars demonstrated that adsorbed $\mathrm{Zn}$ on RB600 were more stable than in others and contains a higher amount of adsorbed $\mathrm{Zn}$ despite the fact that $\mathrm{Zn}$ desorption doesn't seem to occur smoothly. On the contrary, it is more probable to restore adsorbed $\mathrm{Zn}$ in WB300. Adsorption process in acidic state is reversible and $\mathrm{Zn}$ desorption probability following adsorption is substantial. As shown in Table 2, RB300, WB300 were acidic, but in the rest they were alkaline. Results as illustrated in Figure 9 reveal that $\mathrm{Zn}$ desorption was the lowest in RB600 with pH 6.9, but was the highest in WB300 with a pH 5.3. Specific irreversible adsorption rate was shown to be higher in high $\mathrm{pH}$ values.

\section{Conclusions}

The biomass and feedstock type, as well as pyrolysis temperature, have a significant impact on biochar characteristics and correspondingly on $\mathrm{Zn}$ adsorption-desorption capacity in aqueous solutions. Key biochar properties in $\mathrm{Zn}$ sorption include $\mathrm{pH}$, ash content, and specific surface area were increased at higher pyrolysis temperature; however, $\mathrm{H}$ and $\mathrm{C}$ content and oxygen-containing functional groups demonstrated a decrease. Kinetic experiments confirmed that Elovich and exponential models involved the best fit as far as $\mathrm{Zn}$ sorption is concerned. In equilibrium state, Langmuir, Freundlich and Dubinin-Radushkevich showed a good fit for $\mathrm{Zn}$ sorption data with the highest capacity observed in rice based biochars. Adsorption experiments in aqueous systems indicated that the biochars derived at $600{ }^{\circ} \mathrm{C}$ pyrolysis temperature possess a higher capacity for $\mathrm{Zn}$ sorption than biochars pyrolyzed at $300{ }^{\circ} \mathrm{C}$, which was due to high aromaticity and high surface area. It was also observed that with increasing pyrolysis temperature and decreasing oxygen-containing functional groups, no increase in $\mathrm{Zn}$ sorption was detected. This may suggests that $\mathrm{pH}$, aromaticity, ash content and specific surface areas are more effective than surface functional groups. The present study could come up with the highest Zn sorption for RB600 with the desorption falling to the lowest rate. Therefore, RB600 can be used as an economical and environmentally safe sorbent for removal $\mathrm{Zn}$ from wastewater and as an alternative for activated carbon or other water purifiers to treat $\mathrm{Zn}$ in wastewater. This work offers a new alternative to transform biomass waste into a promising adsorbent for $\mathrm{Zn}$ removal from wastewater. The results in this research are expected to provide a firm theoretical groundwork for further application of biochars in the remediation of pollution in soils and sediments. 
All authors contributed to the study conception and design. Material preparation, data collection and analysis were performed by Masoumeh Faryadi Shahgoli, Adel Reyhanitabar ,Nosratollah Najafi and Shahin Oustan. The first draft of the manuscript was written by Masoumeh Faryadi Shahgoli and all authors commented on previous versions of the manuscript. All authors read and approved the final manuscript .

\section{Ethics approval and consent to participate}

This is the original work of the authors. The contents of this manuscript have not been copyrighted or published previously, and there are no directly related manuscripts or abstracts, published or unpublished, by any authors of this paper.

\section{Availability of data and materials}

If original data of this article is necessary it can be presented.

\section{Consent for publication and Authors' contributions}

All authors of this research paper have directly participated in the planning, execution, or analysis of this study, and all authors of this paper have read and approved the final version submitted.

\section{Ethics approval}

The content of this manuscript is not now under consideration for publication elsewhere. It will not be copyrighted, submitted, or published elsewhere, while acceptance by Journal of Environmental Science and Pollution Research is under consideration. Regarding the aims and scope of the journal, all authors and contributors of this work have agreed on submitting the report to Journal of Environmental Science and Pollution Research.

\section{Acknowledgements}

This project is supported by a research grant of the university of Tabriz (number 810). The authors thanks to the University of Tabriz. Also, the authors would like to thank Dr. Massoud Yaghoubi, from the Department of English Language and Literature, university of Tabriz, for accepting to do the English writing editing job.

\section{Disclosure statement \\ No potential conflict of interest was reported by the authors.}

\section{References}

Ahmad M, Rajapaksha, AU, Lim JE, Zhang M, Bolan N, Mohan D, Vithanage M, Lee SS, Ok YS (2014) Biochar as a sorbent for contaminant management in soil and water: a review. Chemosphere 99: 19-33. https://doi.org/10.1016/j.chemosphere.2013.10.071

Abdel-Fattah TM, Mahmoud EM, Ahmed SB, Huff MD, Lee JW, Kumar S (2015) Biochar from woody biomass for removing metal contaminants and carbon sequestration. Journal of Industrial and Engineering Chemistry 22: 103-109. https://doi.org/10.1016/j.jiec.2014.06.030

Abdelhadi SO, Dosoretz CG, Rytwo G, Gerchman Y, Azaizeh H (2017) Production of biochar from olive mill solid waste for heavy metal removal. Bioresource Technolog $244 \quad$ (1): 759-767. https://doi.org/10.1016/j.biortech.2017.08.013

Al-Wabel MI, Al-Omran A, El-Naggar AH, Nadeem M, Usman ARA (2013) Pyrolysis temperature induced changes in characteristics and chemical composition of biochar produced from conocarpus wastes. Bioresource Technology 131: 374-379. https://doi.org/10.1016/j.biortech.2012.12.165

Betts AR, Chen N, Hamilton JG, Peak D (2013) Rates and mechanisms of $\mathrm{Zn}^{2+}$ adsorption on a meat and bonemeal biochar. Environmental Science and technology 47 (24): 14350-14357. https://doi.org/10.1021/es4032198

Bogusz A, Oleszczuk P, Dobrowolski R (2015) Application of laboratory prepared and commercially available biochars to adsorption of cadmium, copper and zinc ions from water. Bioresource Technology 196: 540-549. https://doi.org/10.1016/j.biortech.2015.08.006

Bogusz A, Oleszczuk P, Dobrowolski R (2019) Adsorption and desorption of heavy metals by the sewage sludge and biochar-amended soil. Environmental Geochemistry and Health 41: 1663-1674. https://doi.org/10.1007/s10653017-0036-1 
Cely P, Gasco G, Paz-Ferreiro J, Mendez A (2015) Agronomic properties of biochars from different manure wastes. Journal of Analytical and Applied Pyrolysis 111: 173-182. https://doi.org/10.1016/j.jaap.2014.11.014

Chabani M, Amrane A, Bensmaili A (2006) Kinetic modelling of the adsorption of nitrates by ion exchange resin. Chemical Engineering Journal 125 (2): 111-117. https://doi.org/10.1016/j.cej.2006.08.014

Chen X, Chen G, Chen L, Chen Y, Lehmann J, McBride MB, Hay AG (2011) Adsorption of copper and zinc by biochars produced from pyrolysis of hardwood and corn straw in aqueous solution. Bioresource Technology 102 (19): 8877-8884. https://doi.org/10.1016/j.biortech.2011.06.078

Cheung C, Porter J, McKay G (2000) Sorption kinetics for the removal of copper and zinc from effluents using bone char. Separation and purification technology 19 (1-2): 55-64. https://doi.org/10.1016/S1383-5866(99)00073-8

Cui X, Fang S, Yao Y, Li T, Ni Q, Yang X, He Z (2016) Potential mechanisms of cadmium removal from aqueous solution by Canna indica derived biochar. Science of the Total Environment 562: 517.525. https://doi.org/10.1016/j.scitotenv.2016.03.248

Ding Y, Liu Y, Liu S, Li Z, Tan X, Huang X, Zeng G, Zhou Y, Zheng B, Cai X (2016) Competitive removal of Cd (II) and $\mathrm{Pb}$ (II) by biochars produced from water hyacinths: performance and mechanism. RSC Advances 6: 52235232. https://doi.org/10.1039/C5RA26248H

Doumer M, Rigol A, Vidal M, Mangrich AS (2016) Removal of $\mathrm{Cd}, \mathrm{Cu}, \mathrm{Pb}$, and $\mathrm{Zn}$ from aqueous solutions by biochars. Environmental Science and Pollution Research 23 (3): 2684-2692. https://doi.org/10.1007/s11356-015-5486-3

Frišták V, Pipíška M, Lesný J, Soja G, Friesl-Hanl W, Packová A (2015) Utilization of biochar sorbents for $\mathrm{Cd}^{2+}, \mathrm{Zn}^{2+}$, and $\mathrm{Cu}^{2+}$ ions separation from aqueous solutions: comparative study. Environmental Monitoring and Assessment 187 (1): 1-16. https://doi.org/10.1007/s10661-014-4093-y

Hu Q, Zhang Zh (2019) Application of Dubinin-Radushkevich isotherm model at the solid/solution interface: A theoretical analysis. Journal of Molecular Liquids 277: 646-648. https://doi.org/10.1016/j.molliq.2019.01.005

Jiang Sh, Huang L, Nguyen TAH, Ok YS, Rudolph V, Yang H, Zhang D (2016) Copper and zinc adsorption by softwood and hardwood biochars under elevated sulphate-induced salinity and acidic $\mathrm{pH}$ conditions. Chemosphere 142: 64-71. https://doi.org/10.1016/j.chemosphere.2015.06.079

Jin J, Li Y, Zhang J, Wu S, Cao Y, Liang P, Zhang J, Wong MH, Wang M, Shan S, Christie P (2016) Influence of pyrolysis temperature on properties and environmental safety of heavy metals in biochars derived from municipal sewage sludge. Journal of Hazardous Materials 320: 417-426. https://doi.org/10.1016/j.jhazmat.2016.08.050

Kolodyńska D, Wnętrzak R, Leahy JJ, Hayes MHB, Kwapiński W, Hubicki Z (2012) Kinetic and adsorptive characterization of biochar in metal ions removal. Chemical Engineering Journal 197: 295-305. https://doi.org/10.1016/j.cej.2012.05.025

Kizito S, Wu S, Kirui WK, Lei M, Lu Q, Bah H, Dong R (2015) Evaluation of slow pyrolyzed wood and rice husks biochar for adsorption of ammonium nitrogen from piggery manure anaerobic digestate slurry. Science of the Total Environment 505: 102-112. https://doi.org/10.1016/j.scitotenv.2014.09.096

Lee Y, Park J, Ryu C, Gang KS, Yang W, Park YK, Jung J, Hyun S (2013) Comparison of biochar properties from biomass residues produced by slow pyrolysis at $500{ }^{\circ} \mathrm{C}$. Bioresource Technology 148: 196-201. https://doi.org/10.1016/j.biortech.2013.08.135

Li H, Dong X, da Silva EB, de Oliveira LM, Chen Y, Ma LQ (2017) Mechanisms of metal sorption by biochars: Biochar characteristics and Modifications: A review. Chemosphere 178: 466-478. https://doi.org/10.1016/j.chemosphere.2017.03.072

Mubarak NM, Alicia RF, Abdullah EC, Sahu JN, Haslija AA, Tan J (2013) Statistical optimization and kinetic studies on removal of $\mathrm{Zn}{ }^{2+}$ using functionalized carbon nanotubes and magnetic biochar. Journal of Environmental Chemical Engineering 1 (3): 486-495. https://doi.org/10.1016/j.jece.2013.06.011

Ni BJ, Huang QS, Wang C, Ni TY, Sun J, Wei W (2019) Competitive adsorption of heavy metals in aqueous solution onto biochar derived from anaerobically digested sludge. Chemosphere 219: 351-357. https://doi.org/10.1016/j.chemosphere.2018.12.053

Noh JS, Schwarz JA (1990) Effect of $\mathrm{HNO}_{3}$ treatment on the surface acidity of activated carbons. Carbon 28 (5): 675682. https://doi.org/10.1016/0008-6223(90)90069-B

Oliveira FR, Patel AK, Jaisi DP, Adhikari S, Lu H, Khanal SK (2017) Environmental application of biochar: current status and perspectives. Bioresource Technology 246:110-122. https://doi.org/10.1016/j.biortech.2017.08.122

O'Connor D, Peng T, Zhang J, Tsang DCW, Alessi DS, Shen Z, Bolan NS, Hou D (2018) Biochar application for the remediation of heavy metal polluted land: A review of in situ field trials. Science of the Total Environment 619620: 815-826. https://doi.org/10.1016/j.scitotenv.2017.11.132

Park JH, Ok YS, Kim SH, Cho JS, Heo JS, Delaune RD, Seo, DC (2016) Competitive adsorption of heavy metals onto sesame straw biochar in aqueous solutions. Chemosphere 142: 77-83. https://doi.org/10.1016/j.chemosphere.2015.05.093

Reyhanitabar A, Farhadi E, Ramezanzadeh H, Oustan Sh, (2020) Effect of pyrolysis temperature and feedstock sources on physicochemical characteristics of biochar. Journal of Agricultural Science and Technology 22(2): 547-561.

Salmani MH, Zarei S, Ehrampoush MH, Danaie S (2013) Evaluations of pH and High Ionic Strength Solution Effect in Cadmium Removal by Zinc Oxide Nanoparticles. Journal of Applied Sciences and Environmental Management 17 (4): 583-593. https://doi.org/10.4314/jasem.v17i4.17 
Samsuri AW, Sadegh-Zadeh F, Seh-Bardan BJ (2014) Characterization of biochars produced from oil palm and rice husks and their adsorption capacities for heavy metals. International Journal of Environmental Science and Technology 11: 967-976. https://doi.org/10.1007/s13762-013-0291-3

Shackley S, Carter S, Knowles T, Middelink E, Haefele S, Sohi S, Gross A, Haszeldine S (2012) Sustainable gasificationbiochar systems? A case-study of rice-husk gasification in Cambodia, Part I: Context, chemical properties, environmental and health and safety issues. Energy Policy 42: 49-58. https://doi.org/10.1016/j.enpol.2011.11.026

Thirumavalavan M, Lai YL, Lee JF (2011) Fourier transform infrared spectroscopic analysis of fruit peels before and after the adsorption of heavy metal ions from aqueous solution. Journal of Chemical and Engineering Data 56: 2249-2255. https://doi.org/10.1021/je101262w

Tsechansky L, Graber ER (2014) Methodological limitations to determining acidic groups at biochar surfaces via the boehm titration. Carbon 66: 730-733. https://doi.org/10.1016/j.carbon.2013.09.044

Van Hien N, Valsami-Jones E, Cong Vinh N, Thi Phu T, Thanh Tam NT, Lynch I (2020) Effectiveness of different biochar in aqueous zinc removal: Correlation with physicochemical characteristics. Bioresource Technology Report. 11: 100466. https://doi.org/10.1016/j.biteb.2020.100466

Wang H, Gao B, Wang Sh, Fang J, Xue Y, Yang K (2015) Removal of Pb(II), Cu(II), and Cd(II) from aqueous solutions by biochar derived from $\mathrm{KMnO}_{4}$ treated hickory wood. Bioresource Technology 197: 356-362. https://doi.org/10.1016/j.biortech.2015.08.132

Westerman RL (1990) Soil Testing and Plant Analysis. In: "The Soil Science Society of America Book Series". Third Edition, Soil Science Society of America, Inc., Madison, Wisconsin, USA, 784 PP.

Yang Z, Liang J, Tang L, Zeng G, Yu M, Li Xi, Li Xu, Qian Y, Wu H, Luo Y, Mo D (2018) Sorption-desorption behaviors of heavy metals by biochar-compost amendment with different ratios in contaminated wetland soil. Journal of Soils and Sediments 18: 1530-1539. https://doi.org/10.1007/s11368-017-1856-4

Zhang A, Li X, Xing J, Xu G (2020) Adsorption of potentially toxic elements in water by modified biochar: a review. Journal of Environmental Chemical Engineering 8(4): 104196. https://doi.org/10.1016/j.jece.2020.104196

Zhao M, Dai Y, Zhang M, Feng C, Qin B, Zhang W, Zhao N, Li Y, Ni Zh, Xu Zh, Tsang DCW, Qiu R (2020) Mechanisms of $\mathrm{Pb}$ and/or $\mathrm{Zn}$ adsorption by different biochars: Biochar characteristics, stability, and binding energies. Science of the Total Environment 717: 136894. https://doi.org/10.1016/j.scitotenv.2020.136894 


\section{Figures}

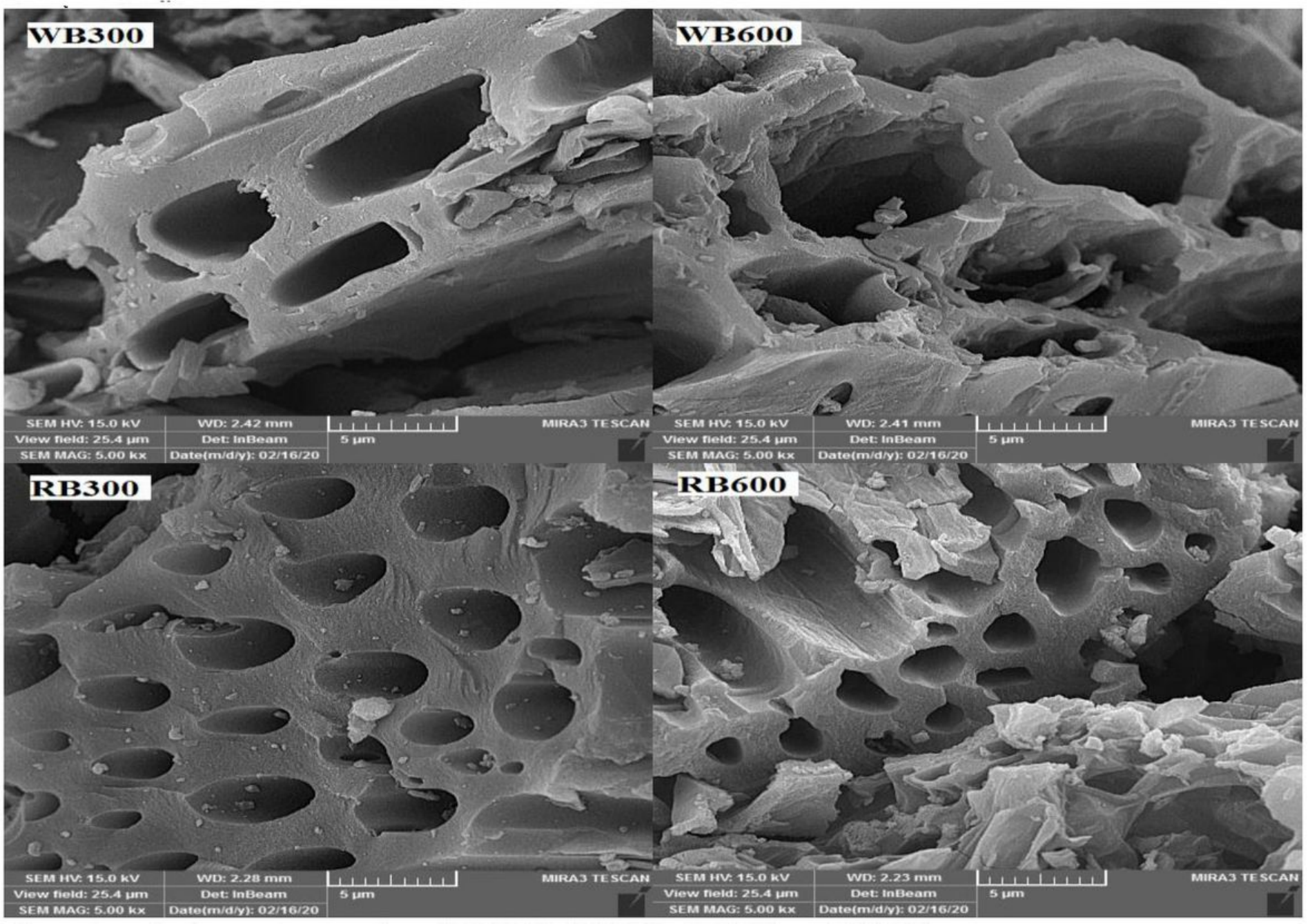

Figure 1

Scanning electron micrographs of WB300, WB600, RB300 and RB600.
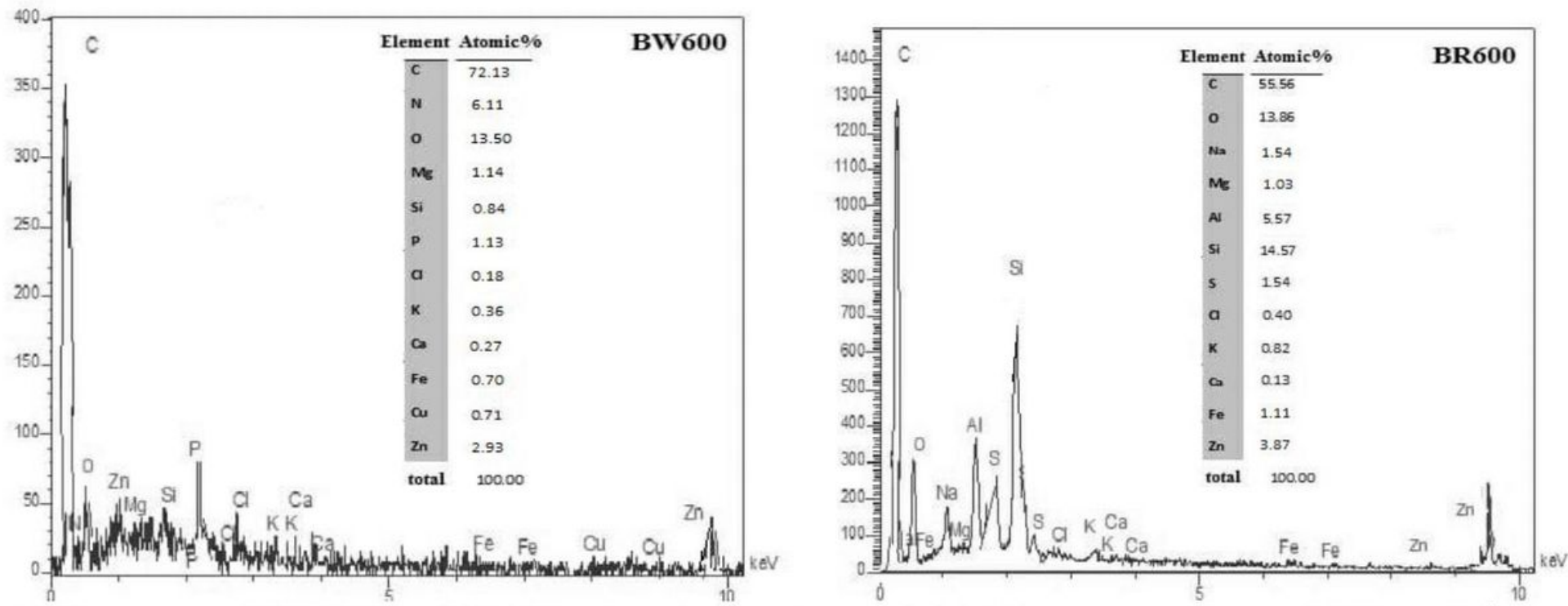
Figure 2

EDX spectra of WB600 and RB600 after Zn sorption, at initial Zn concentration of $200 \mathrm{mg}$ L-1.

(a)

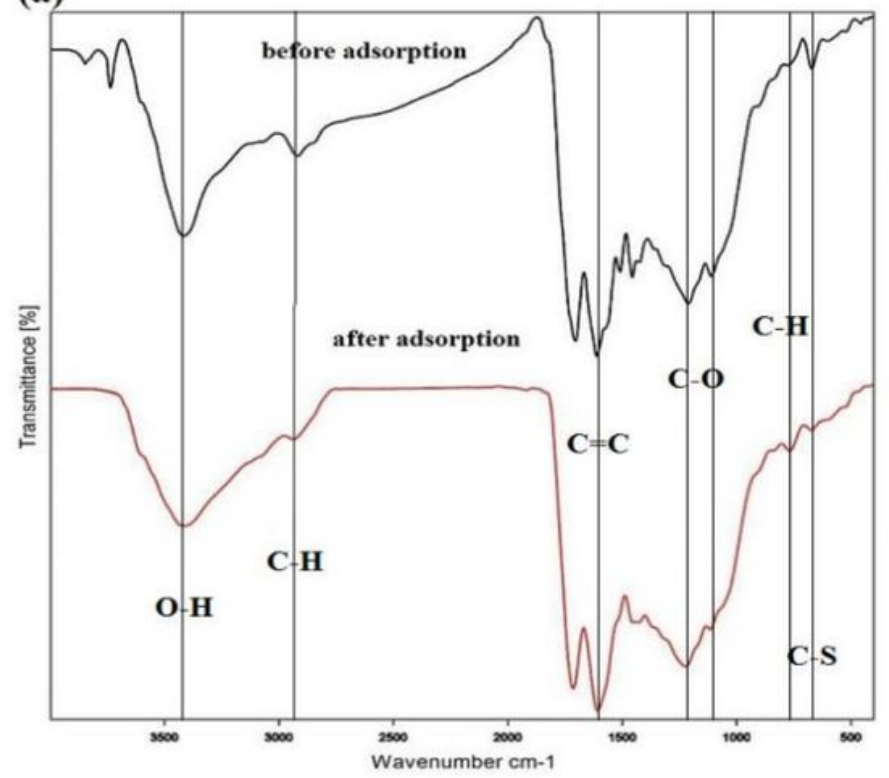

(c)

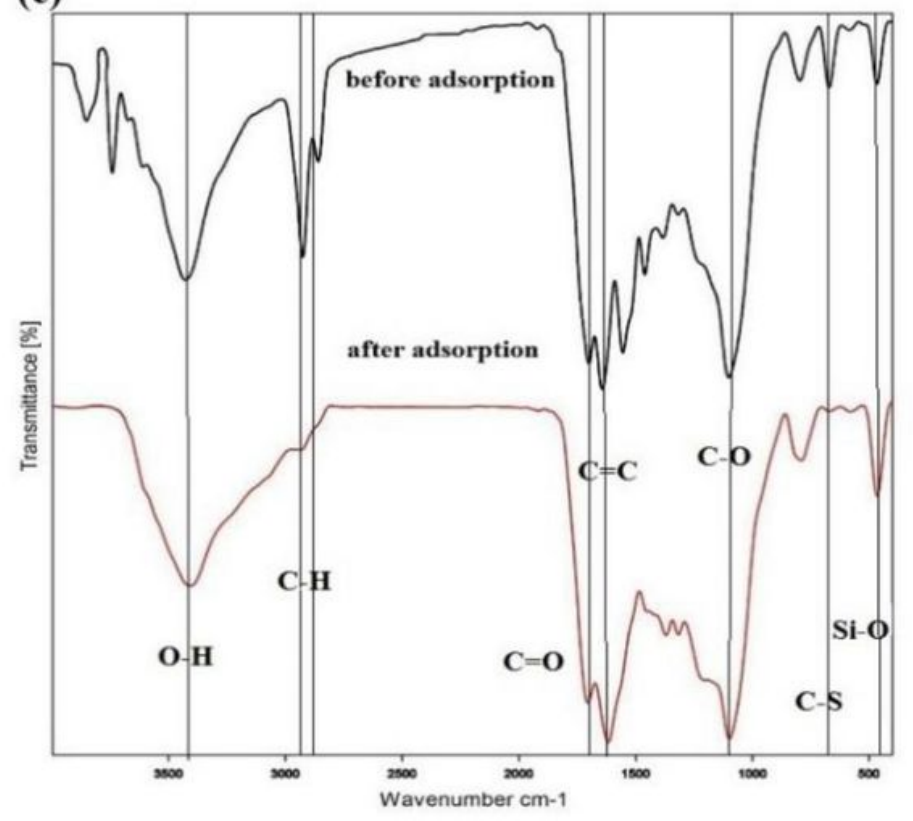

(b)

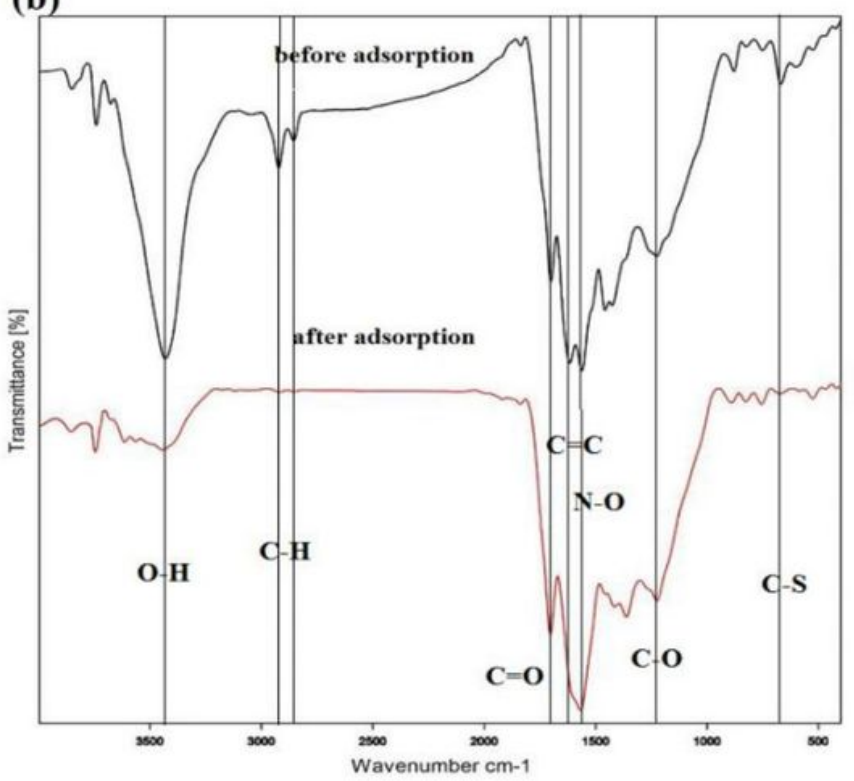

(d)

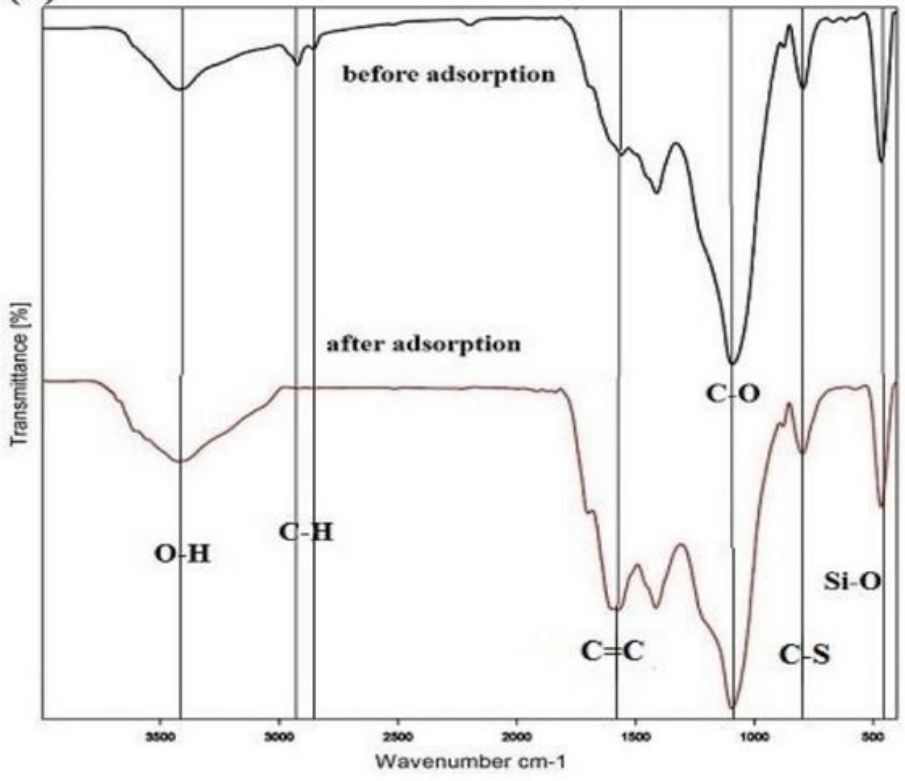

Figure 3

FTIR spectra of WB300, (a) WB600, (b) RB300, (c) and RB600 (d) before and after Zn sorption, at initial concentration of $200 \mathrm{mg} \mathrm{L}-1$. 


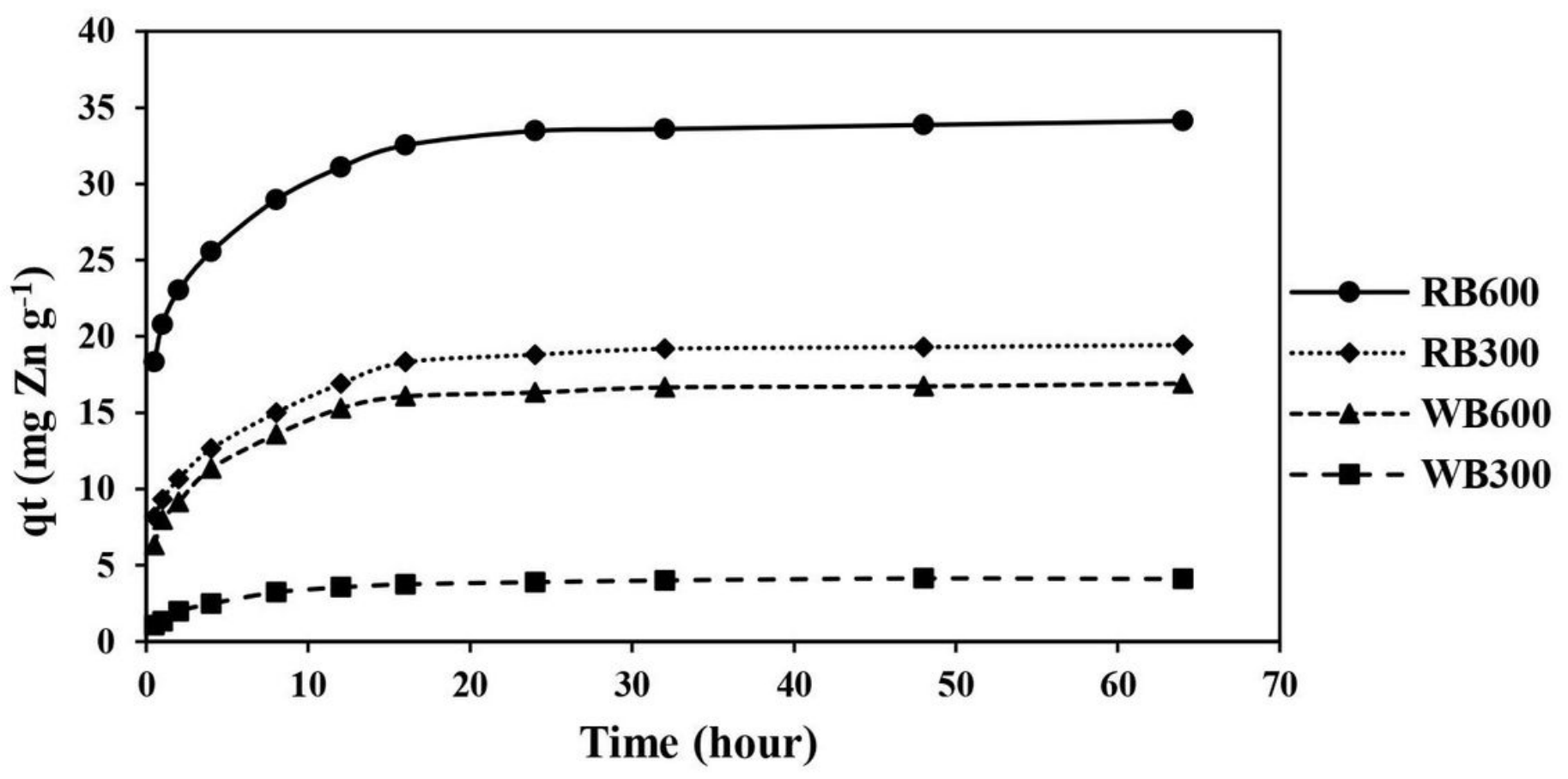

Figure 4

Adsorption kinetics of Zn by different biochars used in this study.

(a)

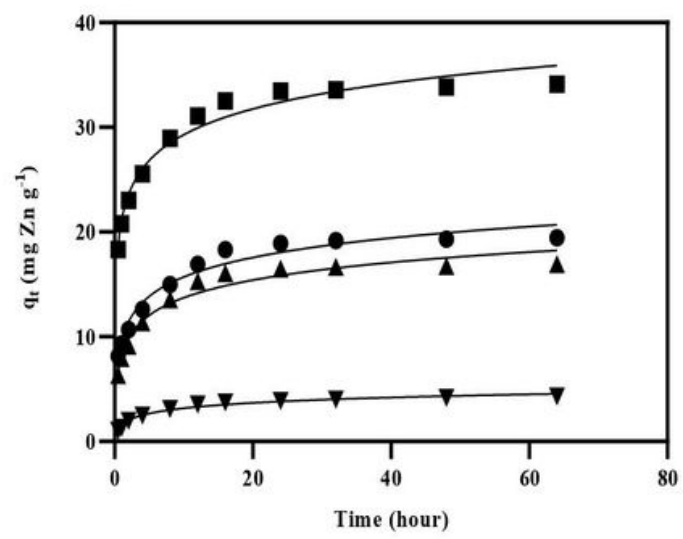

(b)

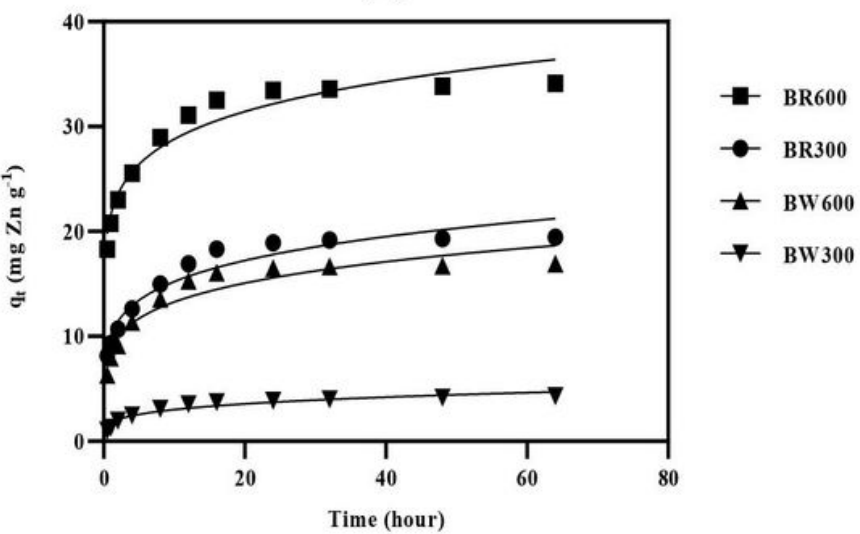

Figure 5

Zn sorption data for the studied biochars (a) the fitting of Elovich equation,(b) the fitting of exponential model. qt is the amount of Zn sorption (mg Zn g-1) at time t. 

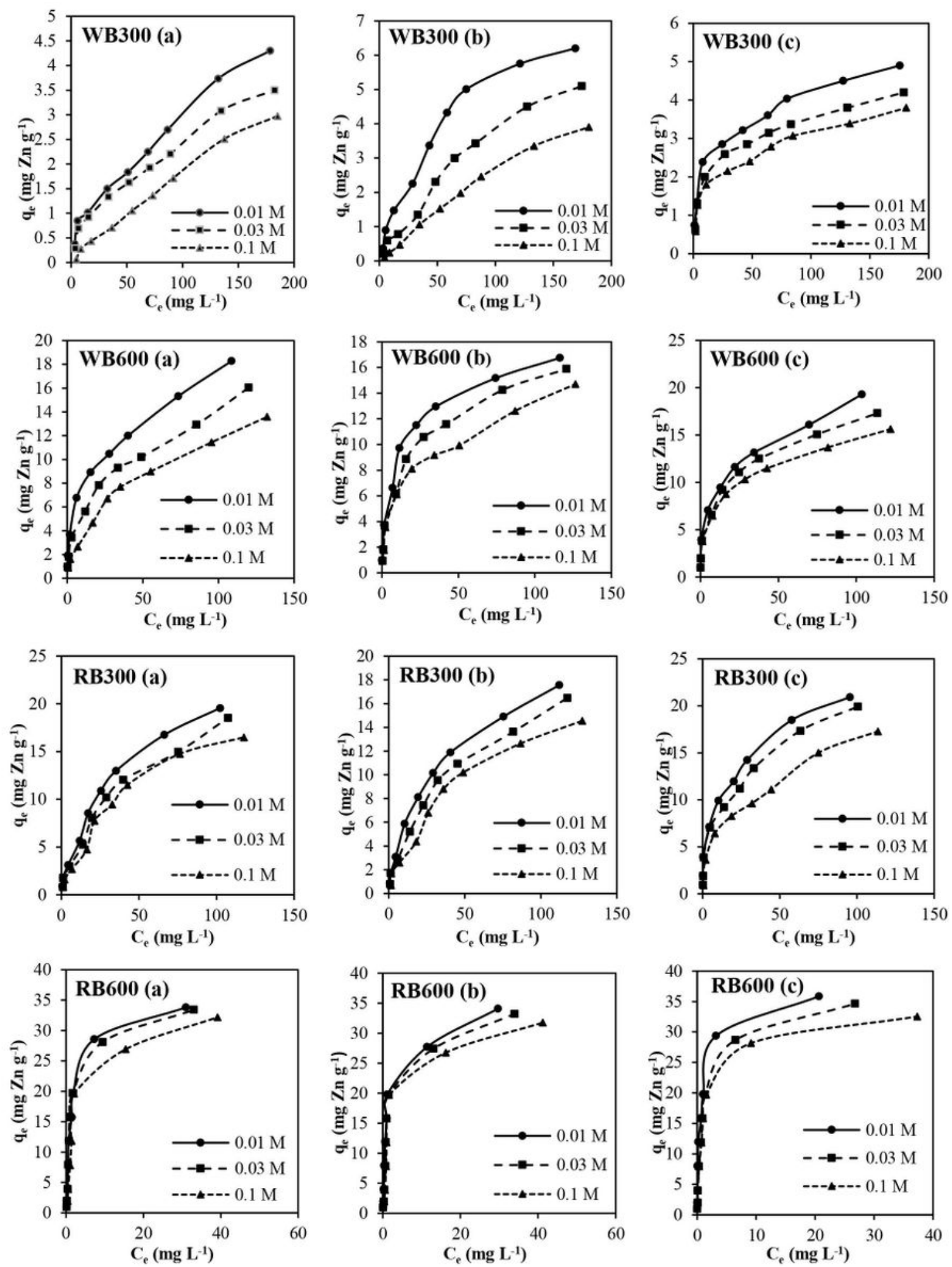

\section{Figure 6}

Zn sorption isotherm data for WB300, WB600, RB300 and RB600 in (a) Unadjusted pH, (b) pH adjusted to 4 and (c) pH adjusted to 6 

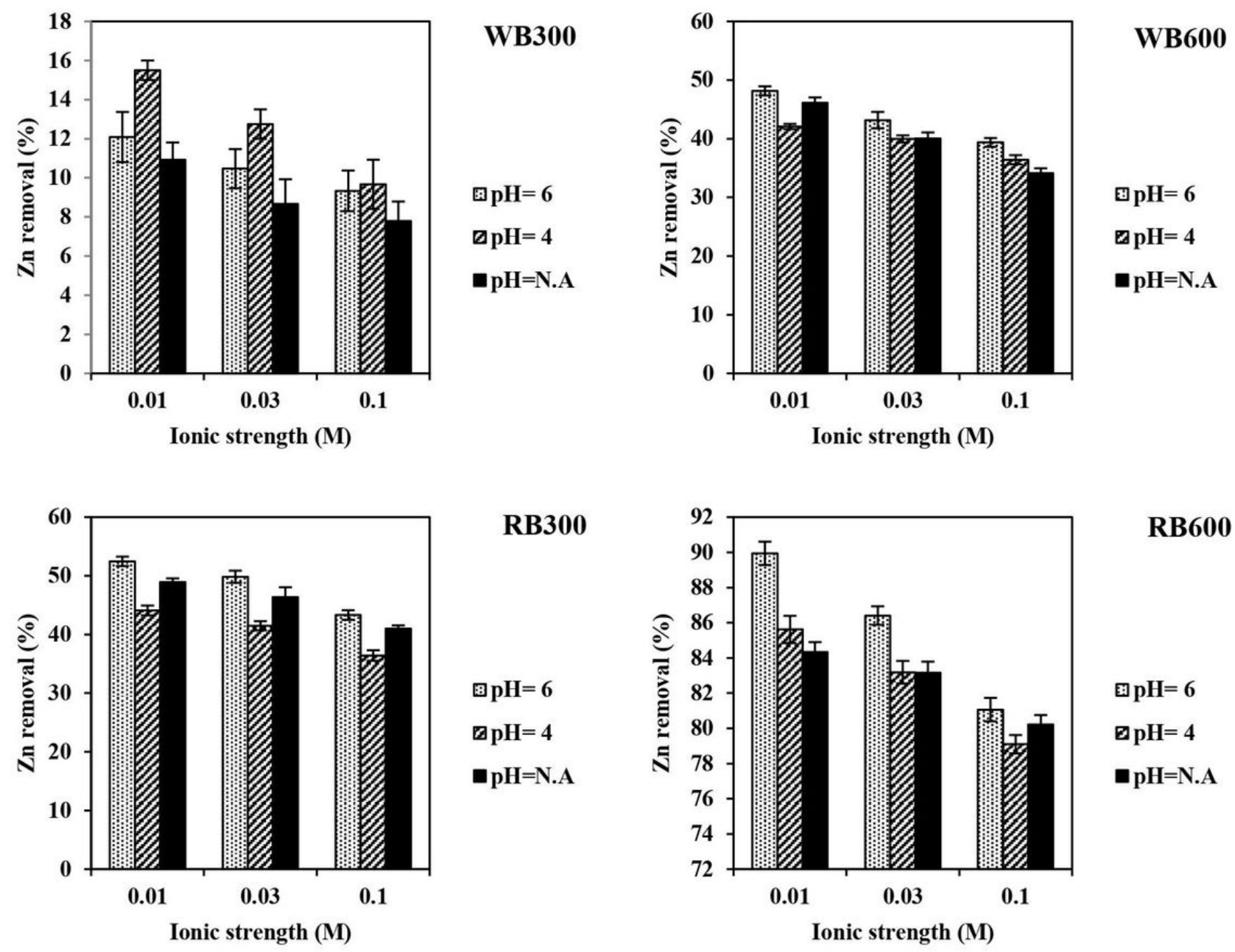

Figure 7

Zn removal in studied biochars at highest initial concentration (200 mg L-1) 
(b)

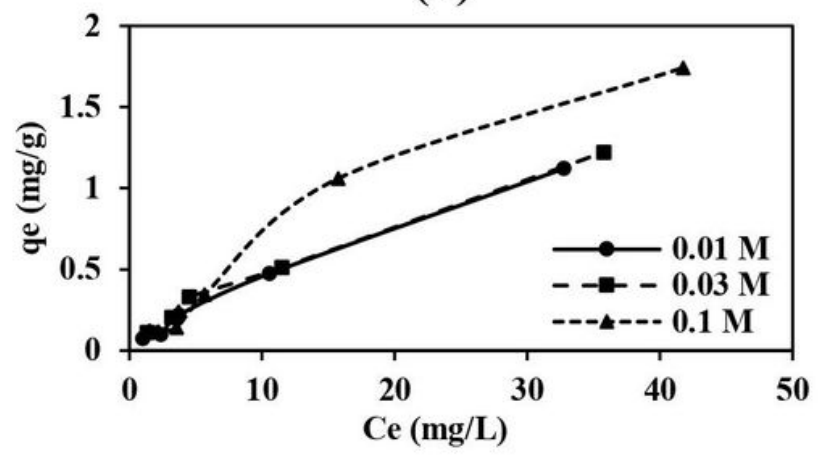

(c)

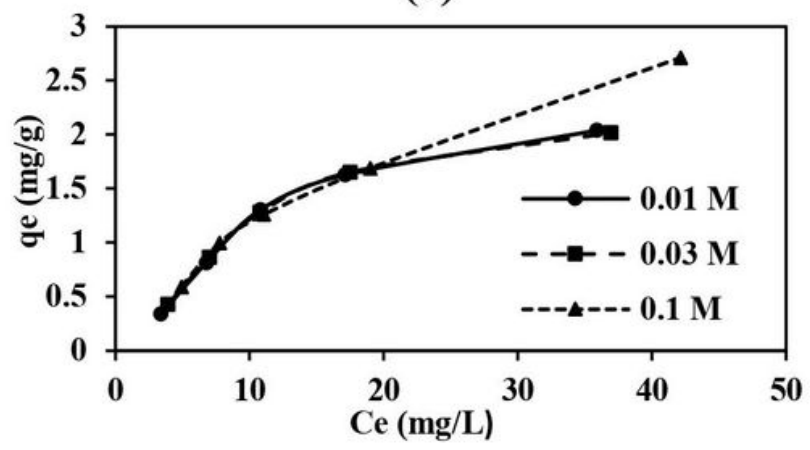

(a)

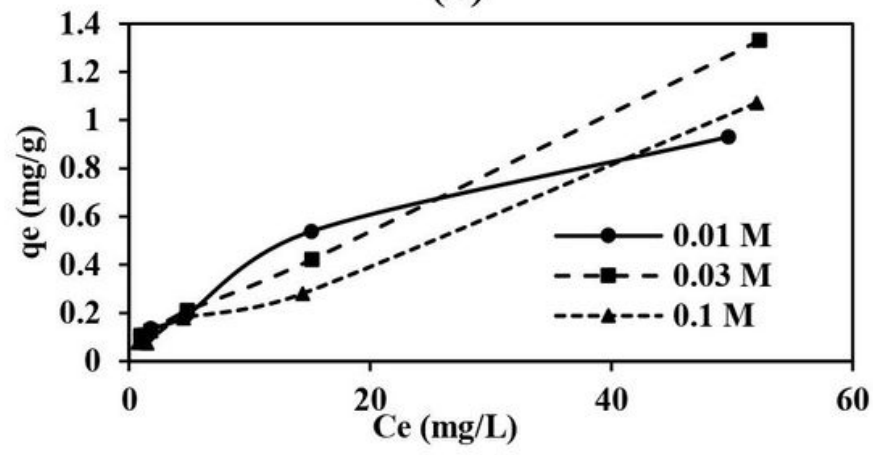

(d)

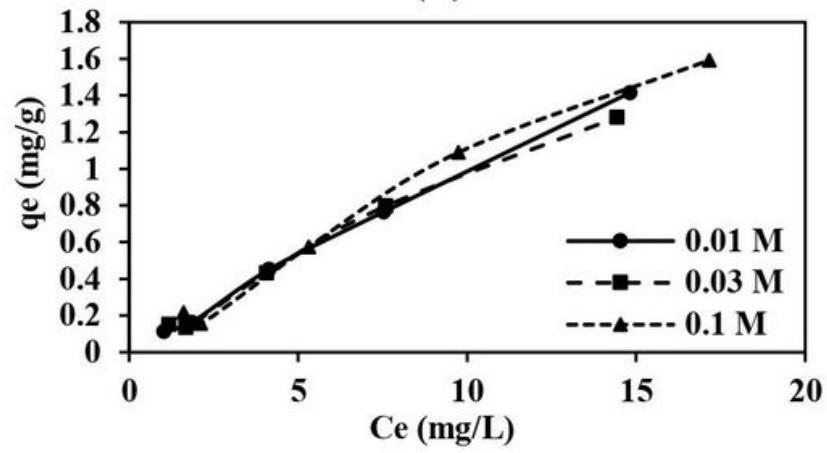

Figure 8

Zn desorption isotherms for studied biochars, WB300 (a), WB600 (b), RB300 (c), RB600 (d) 

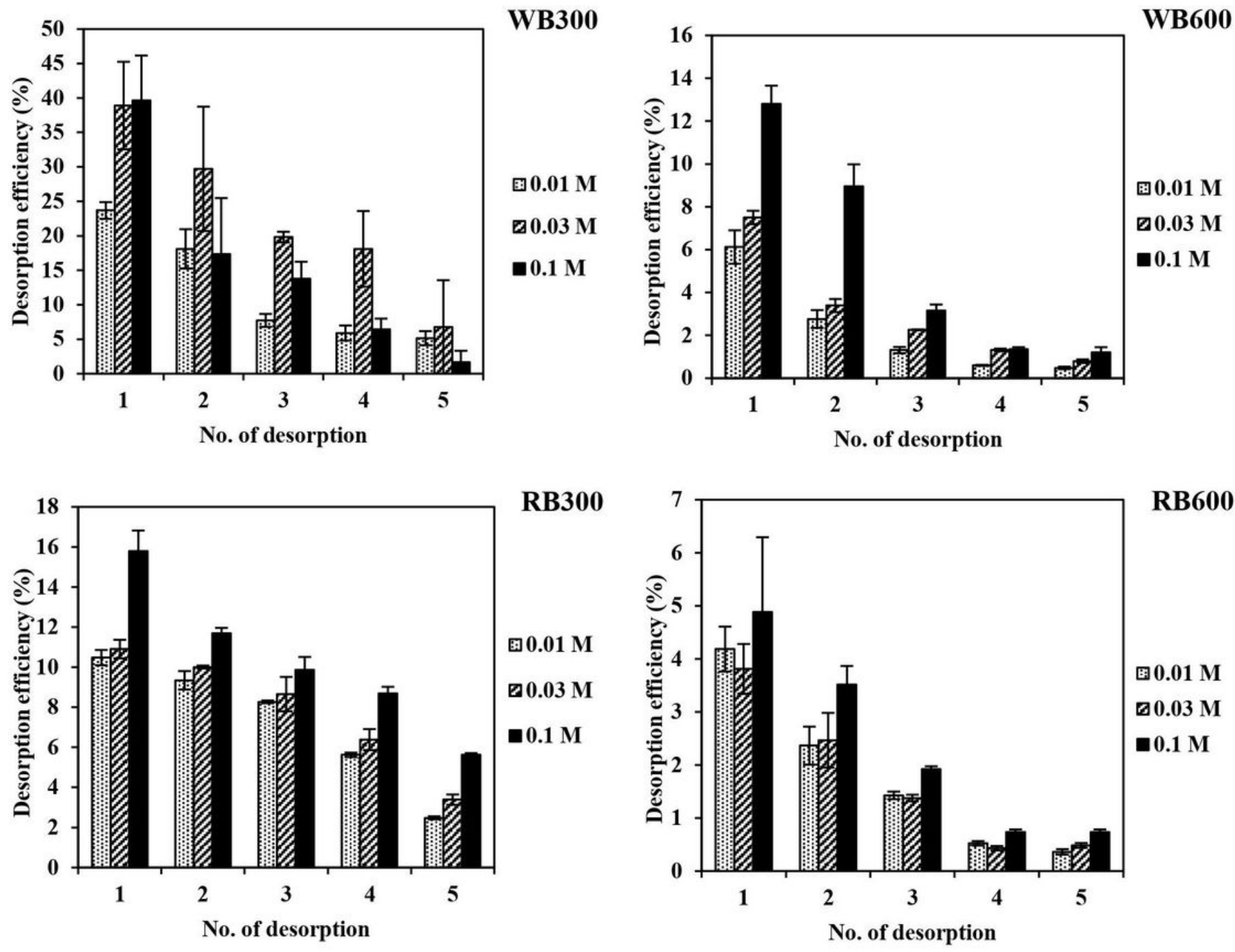

Figure 9

Zinc desorption efficiency of studied biochars in five steps of desorption 